\title{
Decoupled Modelling Approaches for Environmental Interactions with Monopile-Based Offshore Wind Support Structures
}

\author{
Pim van der Male ${ }^{1, *(1)}$, Marco Vergassola ${ }^{1}$ and Karel N. van Dalen ${ }^{2}[$ \\ 1 Department of Hydraulic Engineering, Delft University of Technology, Stevinweg 1, \\ 2628CN Delft, The Netherlands; m.vergassola@tudelft.nl \\ 2 Department of Engineering Structures, Delft University of Technology, Stevinweg 1, \\ 2628CN Delft, The Netherlands; k.n.vandalen@tudelft.nl \\ * Correspondence: p.vandermale@tudelft.nl; Tel.: +31-15-278-3473
}

Received: 13 August 2020 ; Accepted: 22 September 2020; Published: 5 October 2020 updates

\begin{abstract}
To meet the political goals regarding renewable energy production, offshore wind keeps expanding to waters with larger depths and harsher conditions, while the turbine size continues to grow and ever-larger foundation structures are required. This development can only be successful if further cuts in the levelized cost of energy are established. Regarding the design of the foundation structures, a particular challenge in this respect relates to the reduction of the total computational time required for the design. For both practical and commercial reasons, the decoupled modelling of offshore wind support structures finds a common application, especially during the preliminary design stage. This modelling approach aims at capturing the relevant characteristics of the different environment-structure interactions, while reducing the complexity as much as possible. This paper presents a comprehensive review of the state-of-the-art modelling approaches of environmental interactions with offshore wind support structures. In this respect, the primary focus is on the monopile foundation, as this concept is expected to remain the prominent solution in the years to come. Current challenges in the field are identified, considering as well the engineering practice and the insights obtained from code comparison studies and experimental validations. It is concluded that the decoupled analysis provides valuable modelling perspectives, in particular for the preliminary design stage. In the further development of the different modelling strategies, however, the trade-off with computational costs should always be kept in mind.
\end{abstract}

Keywords: monopile support structures; design procedure; aerodynamic damping; hydrodynamic loading; soil-structure interaction

\section{Introduction}

Offshore wind energy is a fast-growing sector and it has proven to be a concrete alternative to fossil fuels. Since the Europe2020 agreement [1] set the target of at least $20 \%$ of the electricity production coming from renewable energy sources by 2020, the cumulative installed capacity of offshore wind turbines in Europe has more than quadruplicated [2]. The increase of installed capacity came along with a general growth in wind turbine size, distance to shore and water depth of the installed and planned wind farms in the last decade. Consequently, researchers and industries had to face and are still facing many challenges regarding design, production, installation, operability, maintenance and decommissioning of these new and bigger offshore wind turbines [3,4].

The current framework, together with the need to cut the levelized cost of energy, boosted the offshore wind research field, as it is demonstrated by the vast amount of papers published in 
the last decade. New foundation concepts are currently investigated for deeper water sites [5-7]. The advancements in the application of design optimization techniques to offshore wind turbines allow to build lighter support structures and consequently to cut the costs [8,9]. Development in wind turbine control systems increased the operability, reliability and electrical efficiency of wind turbines, reduced fatigue loads on the turbine components and allowed for new design solutions for the foundation [10-12]. Nevertheless, despite the great advancement during the last decades, many challenges are still present to definitively cut the cost of offshore wind turbines. Among them, in the opinion of the authors, concerns the assessment of the ultimate and fatigue limit states of the support structures of offshore wind turbines, from preliminary to detailed to optimized design.

The design of an offshore wind turbine requires the time-domain simulation of a wide variety of design load cases. By looking at the design standard [13], it can easily be seen how the number of required simulations quickly goes over several thousands. Therefore, in the last decades, many researchers have attempted to find a general methodology to reduce the computational time required for the design of an offshore wind turbine. In fact, the large number of simulations required slows down the design process and consequently increases the levelized cost of energy. A speed-up of the preliminary design phase provides the opportunity to optimize designs within the allocated time, or even to differentiate designs further within a wind farm, eventually resulting in an overall reduction of the levelized cost of energy. The urge to cut down this time and the related cost flew into two main approaches which aim at the reduction of either (i) the number of simulations or (ii) the computational time required by each of them.

Regarding the reduction of the number of simulations (i), Ref. [14] tried to identify the most critical design load cases from the IEC 61400-3 standard for a monopile substructure holding a 5 MW wind turbine. Since these design load cases were initially derived from the design standards written for the oil and gas and the onshore wind energy industries, the researchers systematically compared a set of design load cases in the attempt of classifying them in order of relevance for the design of an offshore wind turbine. The authors compared the overturning moment at the seabed and the root moments of the blades to identify the severity of each analysed design load case. However, the analysis was limited to those load cases which are not largely affected by the control system design, thus, no turbine faults were considered. Moreover, the obtained results are not general enough since the effect of the environmental conditions on the results was not addressed. Ref. [15] also looked into a way to reduce the dimension of the set of design load cases. This work, however, focused on the implications related to fatigue life estimation. The analysis tried to identify the minimum number of load cases necessary to capture the main environmental contributors to fatigue damage given a certain requirement on the uncertainty. Starting from a very large set, the authors compared the effect of random reduction of the set against a reduced set of design load cases which maintains the same statistical properties as the complete set. The work conducted shows that the latter can produce results which are comparable to those of the complete set. Moreover, it was discovered that the introduced uncertainty grows at a lower rate than the dimension reduction of the set.

A popular approach used to reduce the computational time of offshore wind turbines simulations (ii) entails the decoupling the turbine and support structure models. The reason behind this can also be partially attributed to the current offshore wind industry practice. The integrated design of offshore wind turbines is not a common practice, since the turbine manufacturer and the foundation designer usually do not share the details of their structural designs. As a consequence, the communication between these two parties takes place in terms of interface loads. Therefore, the need to investigate the consequence of the application of decoupling methods is pressing. Ref. [16] looked into the accuracy of the decoupling of the turbine and support structure models. The authors compared the fore-aft response computed with a fully coupled simulation and a decoupled simulation of a jacket-based offshore wind turbine. From the analysis, reasonably comparable values for the mean and standard deviation of the structural response for wind-governed load cases were obtained. Ref. [17] compared results obtained from a fully integrated simulation and those of a decoupled system accounting for 
linear aerodynamic damping. The results showed that even if the aerodynamic damping is nonlinear, it is possible to match the results of a fully coupled—or integrated—simulation if optimization of the damping ratios for different wind speeds is performed.

Both $[16,17]$ focused on the decoupling of the wind turbine rotor from the support structure. However, that is not the only component of an offshore wind turbine that could be decoupled. For instance, Ref. [18] investigated the possibility to derive an effective 1D foundation model based on the in-situ small-strain soil stiffness starting from a full 3D finite-element model for a pile with a small slenderness ratio. This approach was proven to be able to capture the pile response with a small error for the analysed case. Similarly, Ref. [19] developed a one-dimensional model to describe the ice-structure-interaction incorporating also the sea-ice dynamics regarding floe size, wind and current.

Moving from a fully integrated simulation to a decoupled one, different choices can be made, especially concerning environmental loading and load-structure interaction modelling. Consequently, in recent years many different techniques have been exploited resulting in overwhelming literature for those who approach this field for the first time. Therefore, the current state-of-the-art concerning the environment-structure interactions for decoupled modelling is described here and the current main challenges are identified. In this respect, the focus is on monopile-based support structures since this type of foundation still represents the standard at the industry level [20].

In the following section, Section 2, this paper addresses the current engineering practice and presents the definitions for offshore wind turbines that are used throughout this work. Some of the main challenges in designing foundation structures of offshore wind turbines are identified in this section too. The different modelling strategies which are documented in literature-concerning aerodynamic and hydrodynamic excitations and soil-structure interaction-are addressed in Section 3, and the main challenges regarding the decoupled analysis of offshore wind turbines are identified. Section 4 concerns the comparison of existing codes for the load simulation and the published measurement data that can be used for validation purposes. Ultimately, in Section 5, solution approaches to obtain the force distribution of an offshore wind support structures are addressed. These approaches cover the reduction of the number of load cases on the one hand (i), and the further reduction of the structural model (ii), by means of dynamic sub-structuring and frequency-domain analysis, on the other.

\section{Offshore Wind Support Structures-The Engineering Practice}

Whereas the minimization of the environmental impact during the complete life-time requires utmost attention, this work focusses on the design life-time of the support structure of single offshore wind turbines. In this respect, reference is made to the design standard DNVGL-ST-0126 [13], which defines the support structure as the structural component supporting the rotor-nacelle assembly. As an example, Figure 1 provides a schematic representation of a three-bladed monopile-based offshore wind turbine. The support structure itself is sub-divided into the tower, sub-structure and foundation, roughly corresponding to the elements exposed to air, water and soil, respectively.

\subsection{Design Procedure}

The stiffness of the foundation affects the aerodynamic excitation of a wind turbine. In addition, the hydrodynamic action on a support structure induces motions of the turbine rotor, which, as a result, experiences an aerodynamic resistance. For operating wind turbines, this resistance is of significant importance for the force distribution in the structure. As a result, an optimal analysis of the response of an offshore wind turbine requires an integrated design approach. Mainly for commercial reasons, however, the design of most offshore wind turbines takes place in a sequential—or iterativemanner, where one party designs the turbine and tower, and a second party designs the foundation, or sub-structure [21]. The sub-optimal assembly of an onshore wind turbine and a traditional offshore platform can easily be recognized here. 


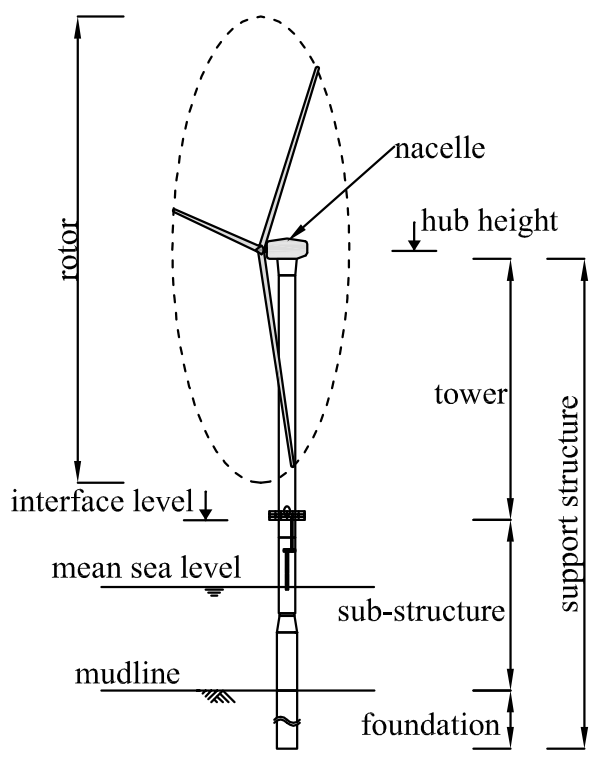

Figure 1. Schematic representation of a three-bladed monopile-based offshore wind turbines with the definitions according to DNVGL-ST-0126 [13].

The design loop of a typical sequential design procedure of an offshore wind sub-structure is illustrated in Figure 2. As a first step, the foundation designer defines an initial geometry of the support structure. This initial geometry can be defined such, that the first natural frequency of the offshore wind turbine does not coincide with the aerodynamic and hydrodynamic frequency bands that contain most energy for structural excitation. In this respect, the rotational frequency of the rotor and the blade passing frequency are of particular relevance [22]. Many researchers suggested closed-form expressions to estimate the first natural frequency of monopile-based offshore wind turbines [23-26], and a procedure for the preliminary design of offshore wind monopile foundations was described by [27], resulting in rules of thumb to estimate the pile geometry for the initial design.

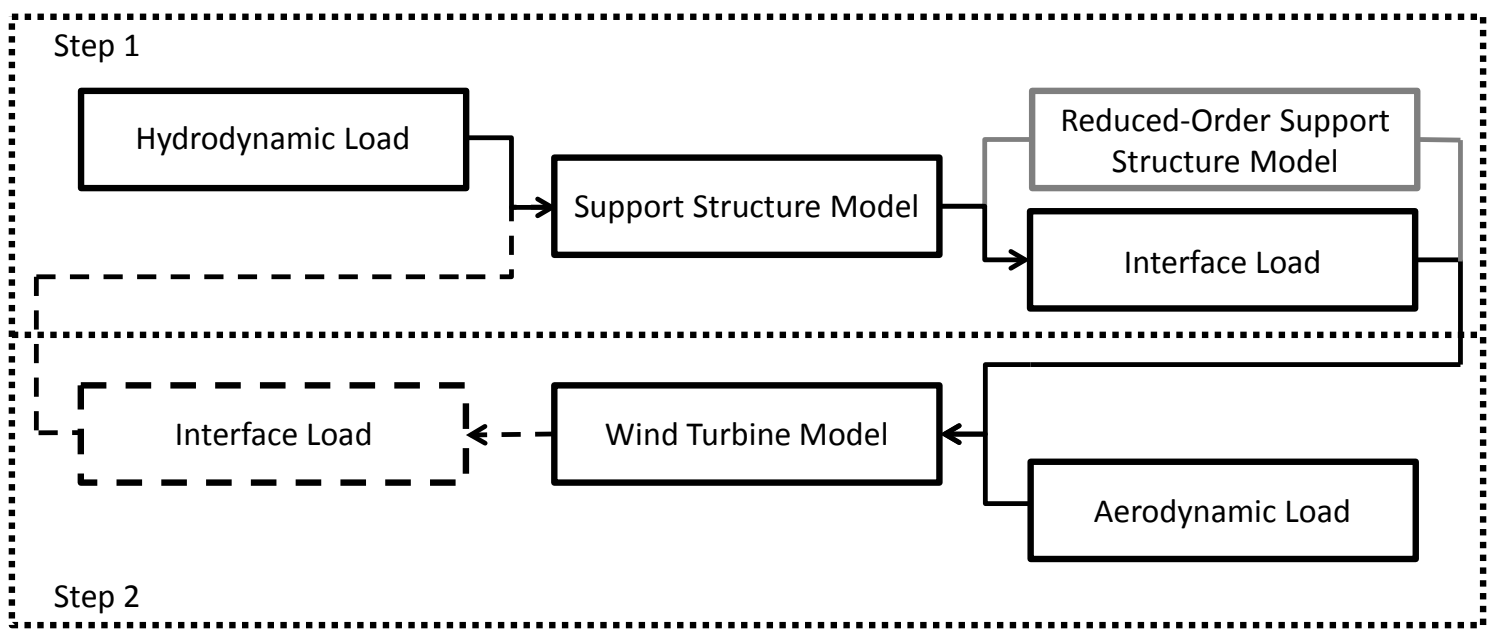

Figure 2. Schematic representation of the sequential design procedure for offshore wind turbines.

After defining the preliminary design of the support structure, the procedure starts with a model of the foundation structure, which is exposed to the hydrodynamic loads (Step 1 in Figure 2). Subsequently, the model-or a reduced-order representation-and the response at the interface with the wind turbine are shared with the turbine designer, who evaluates the structural response of a wind turbine model to the aerodynamic excitations (Step 2). The response at the foundation interface can 
then be used to re-evaluate the structural model of the foundation structure, after which an updated foundation model initiates a subsequent design loop. Ref. [28] provided a detailed description of this design sequence, and [29] specifically addressed the derivation of equivalent interface forces, which are to be shared between the different design parties.

\subsection{Design Challenges}

The design of the support structures of offshore wind turbines involves multiple parties and models of varying complexity. At this point, the design of most offshore wind turbines involves a sequential procedure, requiring multiple iterations for optimized designs. On top of that, while the non-linear nature of the dynamic interactions between the structure and the environment results into digital brain-cracking simulations, the stochastic nature of these excitations imposes the necessity of a large number of such analyses to predict the governing stress distribution in the ultimate limit state and the accumulation of the fatigue damage. Because of these design iterations, the non-linearity of the structural interactions and the stochastic nature of the environmental excitations, the design procedure is incredibly time-consuming. Each design loop requires once again the simulation of the hydrodynamic load cases. Moreover, the aerodynamic analyses neither include the non-linear hydro-elastic coupling, nor the non-linear soil-structure interaction. As a consequence, the sequential design procedure is intrinsically sub-optimal.

Reference [8] identified several challenges regarding the design of offshore wind support structures, the first of which concerns the non-linearity of wind excitations-wake development, dynamic flow, control—and wave excitations-wave slamming—as well as structural non-linearities, mainly from the soil-structure interaction. Vorpahl et al. [30] identified additional structural non-linearities, stemming from the active pitch and torque controls, and the large deflections of the commonly fibre-reinforced composite blades. With respect to the wind conditions, the characteristics of wake turbulence are of importance to evaluate a design within the context of the wind farm. The analysis of the hydrodynamic loads, from both waves and current, requires a valid assessment of both viscous and inertial aspects.

At the same time, the available tools to model for commercial applications do not account for the environment-structure interactions in full. For instance, the aerodynamic inflow is not described for non-uniform conditions and the effect of structural motions is not included. Concerning the hydrodynamic excitation, the load models are only valid for slender vertically submerged rigid cylinders and the action of irregular higher-order waves cannot be described. On the other hand, the available models do not allow for 'quick-and-dirty' preliminary design approaches either, leaving the designer with time-demanding tools, of which the actual accuracy is not fully known. Reference [31] recognized the different levels of fidelity of existing design tools for the different components relevant for the design of an offshore wind turbine. The need for holistic and comprehensive design methods is emphasized, which can be employed for different levels of design uncertainties.

Design analyses are required to assess both the ultimate and the fatigue limit states of the structure during its intended operational life-time. These analyses concern the load conditions during both operational and non-operational states of the turbine, as well as the transitional states of start-up or shut-down, under both normal and emergency conditions. Concerning the latter, the occurrence of turbine faults negatively affecting the internal force distribution requires consideration [32].

The ultimate limit state assessment involves the definition of the extreme sea states and the corresponding extreme wave heights. Given the asymmetry of the support structure, due to the presence of appurtenances, [22] suggested that twelve loading directions should be distinguished. In relating the water level and the extreme wave conditions, it should be noted that the lowest water level may induce breaking waves.

Reference [22] stated that the assessment of the fatigue limit state requires omnidirectional scatter tables, relating wind speeds at hub height to significant wave heights and significant wave heights to wave peak periods. Moreover, the wave directionality should be correlated to the directionality of the wind, ideally in bins of 30 degrees, distinguishing the mentioned twelve directions. If wind 
speed bins of $1 \mathrm{~m} / \mathrm{s}$ are adopted, thousands of environmental states need to be evaluated for the full fatigue assessment.

After the installation of an offshore wind farm, met-ocean data is collected and structural accelerations are measured. These data allow for the validation of the designed structural properties, as well for the monitoring of the structural stress variations. Unfortunately, the amount of data available to the public is limited, but the published results of measurement campaigns reveal a discrepancy between the identified and the modelled dynamic properties. Having the fatigue limit state as a design driver, the most important consequence of this discrepancy is that the real accumulation of the fatigue damage deviates from the predicted accumulation, leaving the actual fatigue life-time of the structure unknown, unless a-posteriori estimation techniques are applied [33].

\section{Modelling Strategies}

The full analysis of an offshore wind turbine requires dynamic structural models of the support structure and the rotor-nacelle assembly, including a model of the control system, coupled to sufficiently large models of the surrounding media, involving the solving of the Navier-Stokes equations for the air and water flows and the applicable constitutive relations for the soil, see Figure 3. To the authors' knowledge, such a comprehensive attempt has not taken place yet. Existing studies focus either on the modelling of one of the media, be it in the realm of academia or engineering [34-38], or on the dynamic description of the controlled offshore wind turbine $[14,39,40]$. The latter case is referred to as the integrated modelling approach, albeit that the full coupling with the surrounding media is not accounted for in full. The structural modelling is based on either finite elements or a multi-body approach, whereas the solution procedure generally involves a Galerkin decomposition. Existing software tools, such as BLADED and FAST [41] allow for the integrated analysis of offshore wind turbines, even though FAST requires coupling with separate modelling modules for the hydrodynamic and soil-structure interaction.

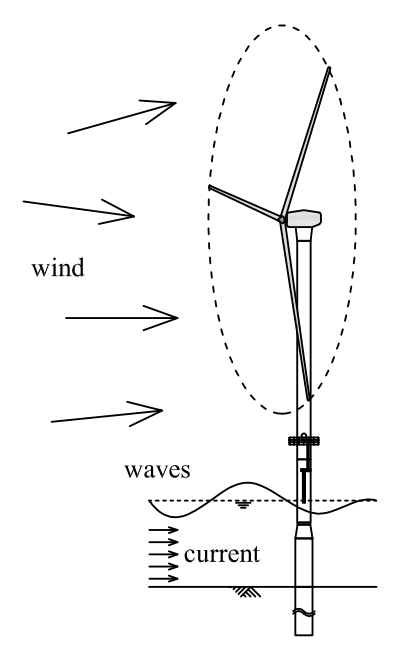

Figure 3. Schematic representation of a three-bladed monopile-based offshore wind turbine exposed to wind, waves and current.

As a further simplification, the rotor-nacelle assembly and the support structure can be analysed in separate models. This so-called decoupled analysis finds practical application in the sequential design procedure, as described in Section 2.1, and in studies solely focussing on either the rotor sub-system or the support structure. The decoupled analysis of the support structure requires the definition of adequate boundary conditions at the tower top, as a substitute of a full rotor model. As an example, Figure 4 illustrates a decoupled support structure, modelled as a non-prismatic Euler-Bernoulli beam, in which the rotor-nacelle assembly is replaced by a concentrated mass at the tower top, an approach which is adopted in many studies [33,42,43], sometimes supplemented by the mass moments of inertia 
of the rigid rotor [44], so that the contribution of the rigid body motion of the rotor-nacelle assembly to the dynamic characteristics of the support structure is accounted for. In this example, the aerodynamic interaction is accounted for by an apparent mass and damping, whereas the soil-structure interaction is represented by distributed springs and dashpots. More realistic representations would account for frequency dependency of the interactions, as well as their non-linear character. Figure 4 does not present the apparent dynamic characteristics of the hydrodynamic interaction-mass and damping - which could affect the global dynamic characteristics of the system too.

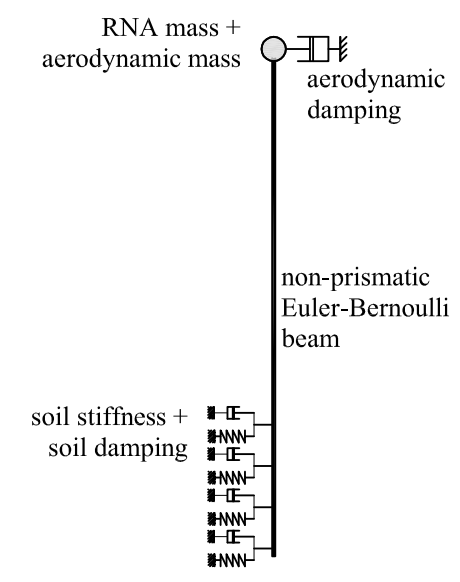

Figure 4. Example of a decoupled model of a monopile-based support structure, with the rotor-nacelle assembly (RNA) replaced by a concentrated mass.

The integrated analysis of an offshore wind turbine requires an explicit description of the different environment-structure interactions, concerning the surrounding fluids-air and water-and the soil. Moreover, the model needs to account for control actions, concerning the generator torque and the blade pitching, to realistically represent the force transfer to the support structure. For the decoupled analysis of a support structure, the aerodynamic rotor excitation including the turbine control is captured by a separate turbine model, and the aerodynamic interaction is accounted for by equivalent tower top forces and an additional damping. The following sections provide an overview of the varying approaches and corresponding challenges to capture the environment-structure interactions in either integrated or decoupled models.

\subsection{Aerodynamic Interaction}

The aerodynamic inflow through the rotor plane of an operating wind turbine generates a circulatory flow around the aerofoil-shaped turbine blades, inducing a lift, see Figure 5. The lift force distributed over the radii of the different blades produces an aerodynamic torque around the horizontal rotor axis, which drives the rotation of the rotor. The rotation of the horizontal axis generates a resisting torque at the generator-through either an indirect or a direct drive-train mechanism. Worth mentioning, in addition, is the fluid power transmission as a most recent development, for which no generator is required in the nacelle at the tower top [45].

Figure 6 depicts the aerodynamic torque and the thrust force on a turbine rotor as a function of the upstream wind speed. At relatively low wind speeds, when the generator does not produce its rated power, the rotational speed of the rotor is controlled by the generator torque. For above rated wind speeds, the torque is kept constant through a pitch control system $[46,47]$. Whereas the aerodynamic torque extracts the energy from the airflow, the wind turbine is exposed to a thrust force, and tilt (Or pitch, the common term in aviation, which in the context of wind turbines may lead to confusion with the control system) and yaw moments too, as well as relatively small side and upward forces. 


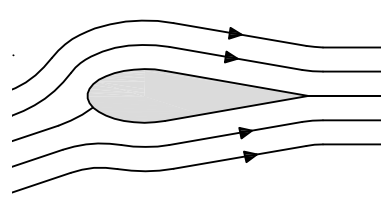

(a)

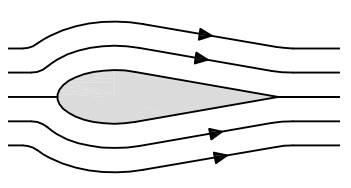

(b)

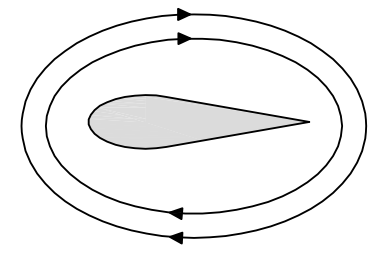

(c)

Figure 5. Schematic representation of the streamlines of an inviscid flow around an aerofoil, with (a) the attached flow for a small angle of attack, (b) a symmetric flow pattern, and (c) the induced circulatory flow.

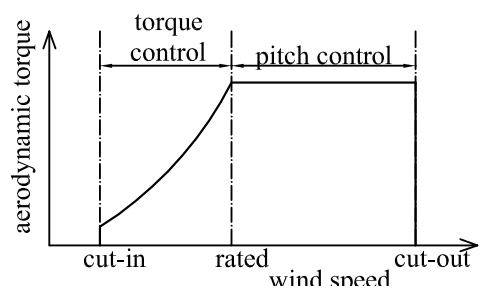

(a)

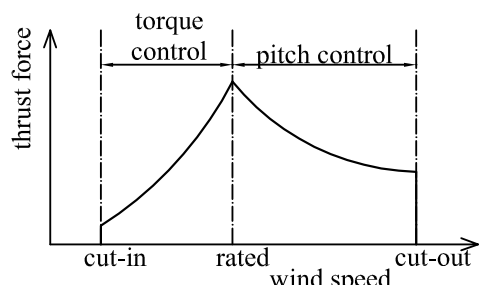

(b)

Figure 6. Schematic representation of (a) the aerodynamic torque, and (b) the thrust force on a turbine rotor as a function of the upstream wind speed.

To a lesser extent, the viscous drag of the flow on the blades contributes to the forcing. Both lift and drag are a function of the relative flow conditions, on the one hand composed of the inflow wind speed and the rotational velocity of the rotor, and on the other hand affected by the structural motions, see Figure 7. The dependency of the aerodynamic forcing on the relative motion is non-linear and history dependent (An aerodynamicist would speak of 'unsteady', which is ambiguous in the field of structural dynamics), implying that the load at a certain instance in time depends on the foregoing flow states. Besides, both forces depend on the inflow angle, or the angle of attack, which is defined as the inflow angle minus the geometrical twist and pitch of the blade. Structural motions induce variations in the angle of attack. For small angles of attack, the dependency of the drag force is negligible, as opposed to the lift force, which moreover is strongly affected by the variations in the angle of attack. The aerodynamic aerofoil forcing has been addressed in both the frequency-domain and the time-domain in the historical works by $[48,49]$.

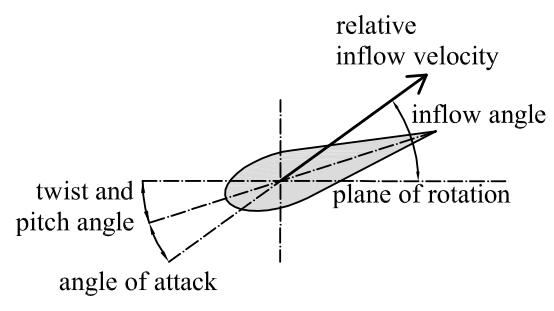

(a)

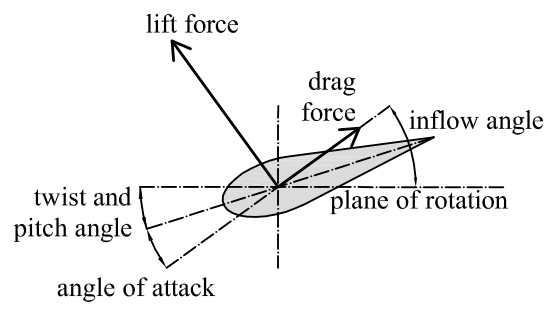

(b)

Figure 7. Schematic representation of (a) an aerofoil exposed to the relative inflow velocity resulting from the wind speed, the rotor speed and the structural motion, and (b) the resulting lift and drag forces acting on that aerofoil.

When considering the rotor as a whole, the flow conditions must obey the conservation laws (mass, momentum). The amount of extracted energy relates to the aerodynamic torque, which in turn results from the aerodynamic forcing on the rotor blades. As a consequence, the analysis of the aerodynamic excitation of a rotating rotor requires the combined analysis of both the global inflow 
conditions and the local blade forcing. This combined analysis is generally referred to as the blade element-momentum theory, which has been extensively described in several textbooks [50-52].

The one-dimensional blade element-momentum theory can account for both axial and tangential flow variations and the apparent inertia resulting from a time-varying inflow. To account for radially varying inflow conditions, the concepts of independent rotor annuli is adopted. For the estimation of the flow field at the rotor plane, the actuator disc concept is applied. The blade element-theory was extended to yawed flows [53], however, the upstream inflow conditions should still be uniform. The free wake vortex ring model, which is based on the discretization of the tubular vortex wake concept, offers an alternative approach to estimate the flow conditions at the rotor plane, for both time-varying and radially varying inflow conditions [54,55]. Approaches to estimate the azimuthal variation of the inflow for finite-bladed rotors require the evaluation of the Biot-Savart law for each time step [56,57], or involve solving the Navier-Stokes equations-representing the rotor blades by actuator lines $[58,59]$ or actuator surfaces $[60,61]$-and quickly lose the applicability for design purposes because of the increasing computational demands. A schematic representation of some different approaches to estimate the flow field is provided by Figure 8. The estimation of the inflow conditions, while accounting for structural motions, requires the coupling of a computational fluid dynamics analysis with a dynamic structural model, a combination requiring tremendous skill and effort [62].

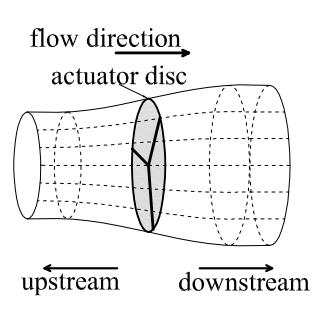

(a)

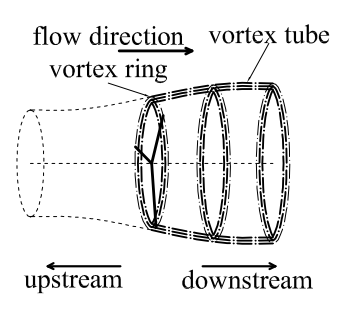

(b)

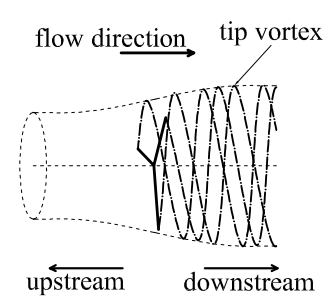

(c)

Figure 8. Schematic representation of different inflow and near-wake modelling approaches, distinguishing (a) the stream tube model for the momentum-balance method, (b) the free wake vortex ring model, and (c) the free vortex wake model.

Structural motions of the rotor also affect the relative inflow conditions, which subsequently affect the aerodynamic forcing on the blades. These motions result from vibrations of the blades, the drive-train or the support structure. Concerning the decoupled analysis of a support structure, the aerodynamic interaction can only depend on the tower top motion, which affects the relative velocity between the inflow and the structure. Despite the non-linear dependency of the aerodynamic excitation on the structural velocity, in decoupled analyses the aerodynamic interaction is commonly accounted for in terms of a modal damping, which is defined for the first mode of vibration only $[63,64]$.

The relevance of the aerodynamic damping for the force distribution of an offshore wind support structure was illustrated by [65]. The estimation of the life-time fatigue damage involves the response analysis to sea states which may induce resonance in the structure. The dynamic amplification at these frequencies is heavily affected by the amount of mobilized damping, to which the aerodynamic damping may give a substantial contribution. Reference [66] derived a closed-form expression for this aerodynamic damping for a constant-speed turbine and attached-flow conditions, based on the analysis of the blade-element forcing on a rigid rotor. The derivation expresses the strong dependence of the damping coefficient on the rotational velocity of the rotor, implying an increase in damping for increasing below-rated wind speeds and a constant maximum damping for above-rated wind speeds. The closed-form expression was extended by [67], who included the drag contribution to the aerodynamic damping and explicitly related the damping to the rotor-induced flow velocities. Moreover, the authors provided an expression for the side-to-side damping of a turbine rotor.

Having an integrated model of an offshore wind turbine available, the aerodynamic damping can be identified as the real part of the complex eigenvalues of the dynamic stiffness matrix [65]. 
This approach does allow for variations in rotor speed and separation of the flow, even though the eigenvalues can only be obtained after establishing a state-independent dynamic stiffness matrix. As an alternative, Ref. [65] suggested to analyse the tower top vibrations of a wind turbine in either steady or turbulent wind conditions after the release of an additional pre-thrust loading, from which the aerodynamic damping can be estimated from the logarithmic decrement of the transient decay. This approach accounts for the state-dependent aerodynamic interaction and can include the contribution of the control system. Regarding the latter, however, the pre-thrust loading will violate the validity of its initial conditions. Moreover, for systems with closely spaced modes, such as the first fore-aft and side-to-side modes of an offshore wind turbine, the identified damping cannot be interpreted purely as modal damping. Whereas [65] implemented an artificial additional thrust force, Ref. [68] identified the aerodynamic damping from the ratio between variations in the thrust force and the wind speed, therefore requiring uniform inflow conditions. Ref. [69] presented a comparison between the latter method and the closed-form expression of [66] with a correction for variable-speed turbines. The different approaches to estimate the aerodynamic damping are summarized in Table 1.

Table 1. Overview of studies presenting approaches to estimate the aerodynamic damping of an operating wind turbine.

\begin{tabular}{ll}
\hline Study & Approach \\
\hline$[66]$ & closed-form expression fore-aft damping \\
{$[65]$} & real part of complex eigenvalue of dynamic stiffness matrix response analysis to additional pre-thrust loading \\
{$[68]$} & ratio of thrust force and wind speed variations- \\
{$[67]$} & extension of [66] including rotor-induced velocities and side-to-side damping \\
{$[69]$} & extension of [66] for variational speed turbines \\
\hline
\end{tabular}

The validity of the model decoupling by means of the application of a single dashpot at the tower top was studied by [16]. In their study, wind turbines with a full-height lattice tower and a lattice-tower hybrid support (or 'jacket') structure were considered. The aerodynamic damping for the decoupled modelling was estimated from the thrust-force derivative with respect to the wind speed. It was concluded that decoupled support structure model with a linear aerodynamic damping gives reasonable mean and standard deviation results when compared to a fully coupled simulation for environmental conditions for wind-force dominated load cases. A lower accuracy was obtained for load cases with a more pronounced wave contribution.

Instead of assuming a single discretized dashpot acting in the fore-aft direction, or estimating the total aerodynamic damping in the modal domain from an integrated analysis, Ref. [17] distinguished the damping for the six translational and rotational motion of the tower top. The corresponding damping values are obtained from an optimization procedure, relating the decoupled support structure model to an integrated wind turbine model. It was shown that the decoupled model with the six dashpots gives a much better fit with the integrated model than a decoupled model with a single fore-aft dashpot. Additionally, it was observed that the aerodynamic damping increases for higher wind speeds, also for above-rated velocities. It was suggested, however, that a linear damping model does not suffice to describe the aerodynamic interaction.

In addition, the control system of the turbine allows for variations of the rotational speed and the pitch angle of the blades, affecting the relative inflow and the angle of attack. Apart from optimizing the power output of the wind turbine, the control system can also be employed to control the motion of the support structure [70]. Individual pitch control systems, which affect the pitch angle of each blade separately offer the possibility to reduce asymmetric loads on the rotor plane, for instance resulting from altitudinal wind speed variations [71-73]. Alternatively, Ref. [74] studied the influence of both the generator torque and pitch control systems on the mitigation of side-to-side motions. Ref. [75] presented a generator torque control system with the same purpose.

In conclusion, the available literature reveals a need for closed-form expressions for the aerodynamic damping corresponding to the six translational and rotational tower top motions. The resulting 
aerodynamic damping matrix, which establishes the relation between the structural motions and the resulting aerodynamic forces, should account for off-diagonal contributions as well. Such a matrix should cover the varying conditions within the operational range of the wind turbine. Furthermore, the underlying assumptions regarding the aero-elastic modelling, including attached flow conditions and the effect of the control system should be regarded, and the validity of a linearization should be assessed. It could be considered to account for higher-order contributions of the aerodynamic interaction as well, even though this immediately impairs the computational efficiency.

\subsection{Hydrodynamic Interaction}

The implementation of the hydrodynamic excitation requires the selection of valid wave and force models. Figure 9 illustrates the validity of different wave theories for varying water depths and wave heights. Provided that the wave steepness is small, the waves can be modelled linearly. The linear wave theory can be applied straightforwardly to define stochastic sea states too. For shallow waters and/or high waves, the linear wave theory is no longer valid and the definition of the wave profile requires higher-order harmonic corrections [76,77], or breaking wave theory should be adopted. The profiles of these different waves is depicted in Figure 10 and an overview of the different wave theories can be found in [78].

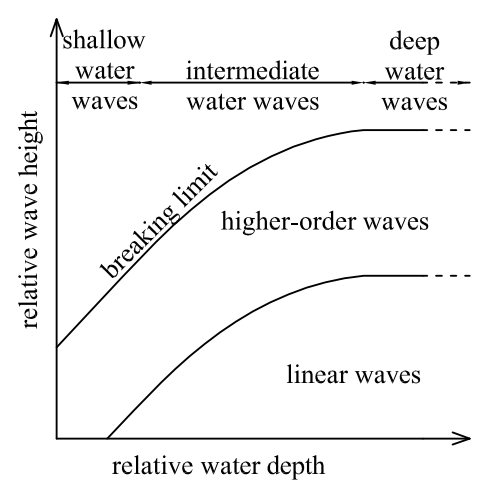

Figure 9. Schematic representation of the different wave-theory regimes for varying water depths and wave heights.

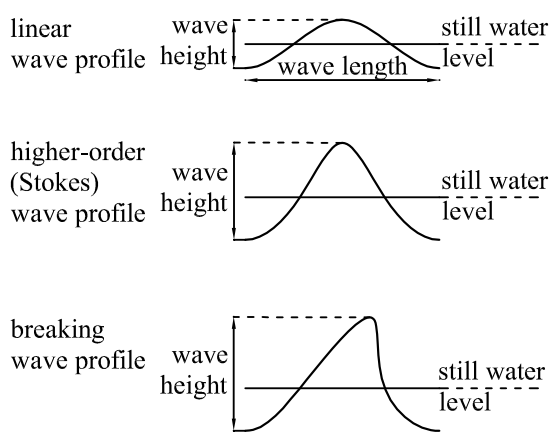

Figure 10. Schematic representation of wave profiles corresponding with different wave theories.

In practical situations, non-linear waves are defined deterministically. To analyze the response to non-linear waves in a random sea, Ref. [79] suggested that a linear stochastic wave model could be applied to determine the initial conditions for the assessment of the excitation of a regular non-linear wave. The propagation of non-linear gravity waves in irregular seas can be evaluated with the 
potential theory, using non-linear free surface boundary conditions. Ref. [80] generated irregular nonlinear wave profiles by employing the second-order correction proposed by [81]. To increase the computational efficiency, Ref. [82] proposed a domain-decomposition strategy, in which the occurrence of non-linear waves is assessed in a linear irregular wave profile, after which a non-linear wave profile is determined to replace the linear profile in a sufficiently large domain, using a higher-order boundary-element method. This approach is schematized in Figure 11.

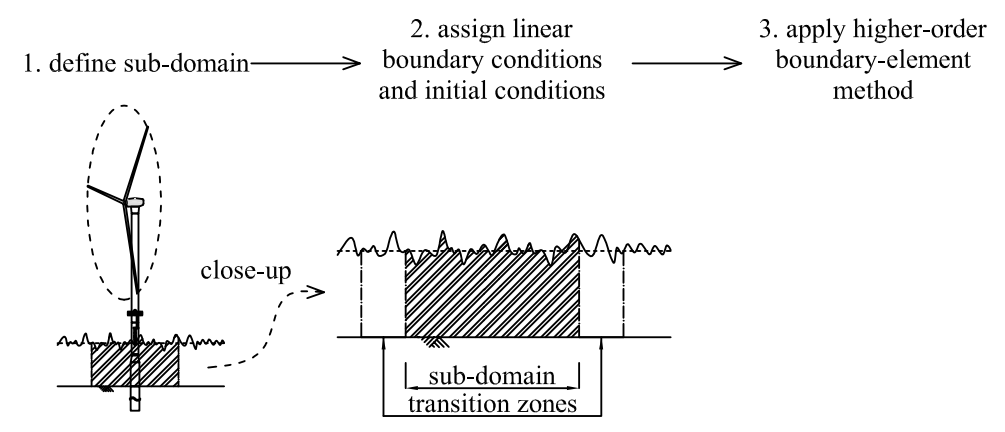

Figure 11. Schematization of the sub-domain analysis approach of non-linear irregular waves [82].

Once the wave kinematics have been adequately defined, the Morison equation can be employed to predict the resulting forces on submerged vertical slender cylinders [83]. The equation distinguishes the inertia force, composed of the Froude-Krylov and the added mass components-as predicted by the potential flow theory - and the drag force resulting from the viscosity of the flow, and requires the definition of time-averaged added mass and drag coefficients, which depend on the shape of the structure, the Reynolds regime and the history of the relative motion between fluid and structure. The empirical Morison equation can be applied to structures that do not significantly affect the incident wave field, provided that the predicted force is either drag or inertia dominated [84]. This is illustrated by Figure 12, with Figure 12a depicting the disturbance of the incoming wave field by a cylindrical structure, and with Figure 12b indicating the governing hydrodynamic force on a cylinder based on the ratios between the wave length and height and the diameter of the cylinder. For shallow waters and/or non-slender cylinders, the effects of wave diffraction and reflection can no longer be neglected. On the basis of linear potential theory, and therefore linear waves, Ref. [85] derived the hydrodynamic inertia force for a cylinder, accounting for both effects. For an elaborate overview of the wave force models on cylindrical structures, reference is made to [84,86].

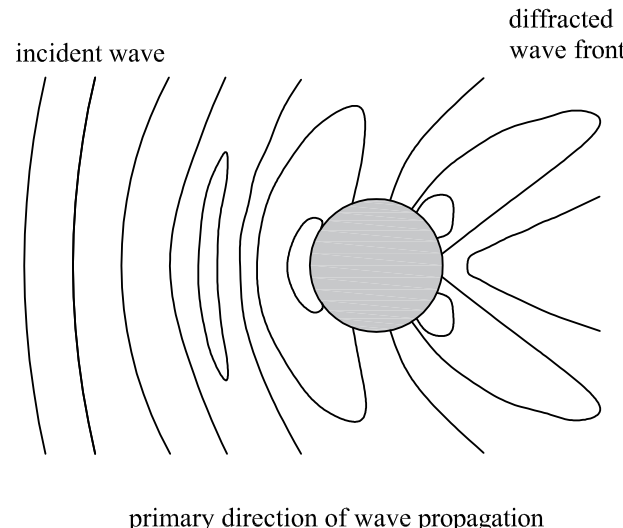

(a)

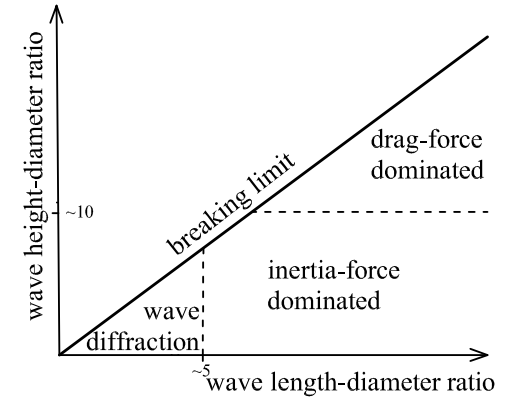

(b)

Figure 12. (a) Schematic representation of the diffracted wave field around a cylindrical structure [87], and (b) the governing hydrodynamic force on a cylindrical structure as a function of the wave length-diameter and wave height-diameter ratios. 
To account for the hydrodynamic interaction with a flexible structure, the hydrodynamic force expressed in terms of the relative kinematics between the fluid particles and the structure, implying that the structural velocity affects the drag force and the structural acceleration the added mass component of the inertia force [88]. It should be noted that the coefficients for drag and inertia of the Morison equation, which are for rigid structures, may lose their validity for this adaptation [84]. Regarding the dynamic response of a monopile-based wind turbine to irregular waves, Ref. [89] conducted model scale experiments for a $7 \mathrm{~m}$ diameter support structure. The results demonstrated the contribution of the second mode of vibration for a parked turbine under extreme sea state conditions.

For increasing wave heights, induced by the wind in developing seas or resulting from wave-wave interactions in random seas, the water particle velocity in the crest of the wave may reach the wave celerity, as a result of which the wave breaks [90]. Reference [91] compared the measured kinematics of resulting so-called 'spilling breakers' with predictions through Dean's stream theory and found the measured velocities and accelerations in the crest region to be slightly higher. Computational fluid dynamics approaches to model the kinematics of spilling breakers were presented by [92,93]. Reference [94] studied the wind-wave energy transfer for the development of steep waves in the vicinity of offshore wind turbines.

Plunging breakers occur when moderate waves run up a seabed slope, enforcing the wave to break. Computational fluid dynamics techniques are commonly employed to study the wave impact on cylindrical structures, such as monopile-based offshore wind turbines [95-97]. Reference [98] modelled the wave kinematics of a plunging breaker by means of their domain-decomposition strategy and estimated the impulsive force on an offshore wind turbine with an analytical impact model. Reference [99] performed a detailed laboratory study on the mechanics of plunging wave impacts on vertical cylindrical structures. Experimental results of breaking wave excitations of a flexible vertical cylinder with a top mass, resembling an offshore wind turbine, were presented by [100]. The experiments showed how breaking wave events induce an impulsive excitation of the first mode of vibration, while the second and the third modes were excited too.

The difficulty of predicting hydrodynamic forces for regimes within which fluid-structure interaction is of relevance was mentioned by [31] as an important long-term research for offshore wind. Especially the impact load from breaking waves still requires a description in terms of time-history and statistical characteristics. Additionally, it is recognized that the existing concepts for stochastic non-linear waves 'are based on spectral synthesis and the superposition principle of linear wave theory'. The need for a useful concept for non-linear irregular waves is expressed. Moreover, as computational fluid dynamics do not provide an applicable approach for design purposes, the Morison equation and the potential flow theory may lose their validity for larger and novel foundation concepts, generating the need for mid-fidelity modelling approaches.

Apart from the hydrodynamic action from waves and currents, certain regions require the analysis of the action of floating level ice, ice floes and ice ridges on the support structures of offshore wind turbines. The prediction of loads from ice requires sufficient data regarding the ice thickness, drifting speed and strength, where the latter relates non-linearly to the rate of loading. Thus, in interaction with vertical-sided structures, the pattern of the structural motion varies with the relative incident velocity of the ice, for which the following regimes for increasing ice speeds are distinguished: intermittent crushing, frequency lock-in and continuous brittle crushing, see Figure 13.

Several models have been developed to predict the loads from the interaction between floating level ice and vertical-sided compliant structures [101-103], recognizing the relevance of the relative incident velocity and assuming a specific crushing length, or applying an effective negative damping to account for the non-linear dependency of the ice strength on the relative motion. These approaches, however, have failed to predict the measured ice loads over a sufficiently wide range of drifting speeds. A phenomenological model developed by [104], and validated in $[19,105]$, recognized the dependency of the contact area between ice and structure on the speed of loading. With the application of this approach, which was already applied in an integrated analysis of an offshore wind turbine [106], 
the modelling of the non-linear ice-structure interaction requires the distinction of a sufficient number of elements in the contact area between the ice and the structure, significantly enhancing the duration of the required load simulations. Still, the existing model only accounts for one-directional ice-structure interaction, whereas the aerodynamic forcing excites the offshore wind turbine in both the fore-aft and the side-to-side directions. An extended analysis of the interaction in two directions is therefore required. On a different note, large uncertainty exists regarding the occurring ice conditions throughout the life-time of offshore wind turbines. Similar to the concept of sea states which are used for the long-term statistics of the ocean conditions, so-called 'ice states' would serve the ultimate and fatigue limit state analyses of wind turbines in ice-exposed regions, requiring an extended database of occurring ice conditions.

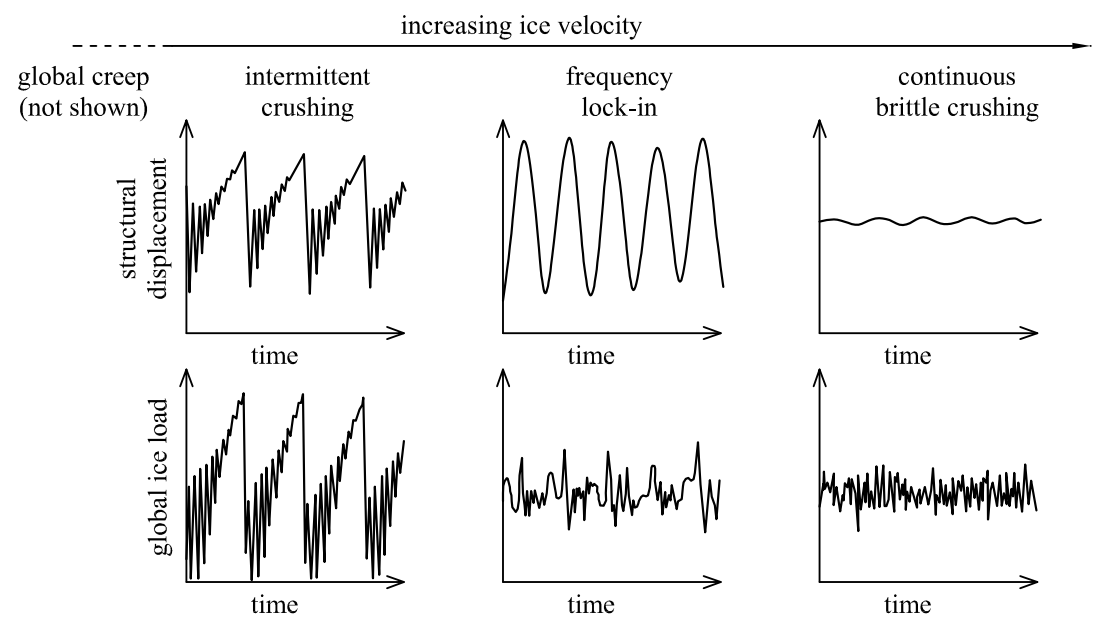

Figure 13. Illustrations of ice-load and structural-response patterns of vertical-sided structures in interaction with ice with varying speed. Adapted from 'Dynamic response of an offshore structure interacting with an ice floe failing in crushing' by Hendrikse, H. and Nord, T. S. (2019), Marine Structures, 130, p. 274. Copyright 2019, Elsevier Ltd.

In analyzing the dynamic response of an operating offshore wind turbine to either hydrodynamic or ice loads, the corresponding aerodynamic interaction cannot be neglected, given the substantial contribution to the damping of the system. As the aerodynamic damping is commonly accounted for in terms of the ratio of the critical damping per mode of vibration, an understanding of the modal contributions to the total response is important. Given the non-linear nature of the interactions between the structure and hydrodynamic actions-particularly breaking waves—and ice loads, response contributions from higher global bending modes cannot be neglected regardless, especially from modes with relatively large modal amplitudes around the sea level [107]. For such modes, the contribution to the critical damping from the aerodynamic interaction may result to a lesser extent from the lateral motion of the tower top, the motion which is considered dominant for the modal damping of the first mode, whereas the nodding motion may provide a considerable contribution. In principle, integrated models intrinsically account for the aerodynamic damping contribution for the varying motions from the different modes of vibration, provided that the mode shapes are estimated accurately. Decoupled modelling approaches, however, require more advanced representations of the aerodynamic damping, to avoid erroneous contributions to the damping ratios of higher bending modes.

\subsection{Soil-Structure Interaction}

For monopile-based support structures, which represent the vast majority of the installed offshore wind turbines, the main soil-structure interaction takes place laterally. This interaction varies with the soil characteristics, e.g., the density, the cohesion, the over-consolidation ratio. Close to the surface, the soil fails in wedges, whereas at deeper layers circumferential sliding of the soil will take place, 
see Figure 14. For offshore wind applications, not just the ultimate resistance of the soil is of importance. The structural response to the time-varying excitations of wind and waves relies on the dynamic stiffness of the soil and the damping through radiation and hysteresis.

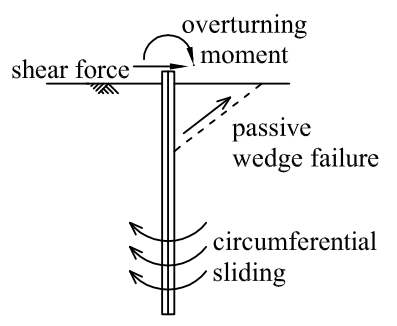

Figure 14. Schematic representation of the soil-failure mechanisms for laterally loaded piles.

The industry-standard approach to model the soil-structure interaction of laterally loaded piles is the $p-y$ curve method [13], an overview of which is provided by [108], which defines the interaction in terms of non-linear force-deflection relations, see Figure 15. For soft normally consolidated marine clay, this method finds its basis in the empirical testing of piles with a diameter of $0.32 \mathrm{~m}$ and an embedded length of $12.80 \mathrm{~m}$ [109], implying a length-diameter ratio of approximately 40 . Tests were performed for short-term static loading, cyclic loading (corresponding to emerging storm conditions) and subsequent reloading with forces smaller than the previous maximums. References $[110,111]$ presented $p-y$ curves for soils consisting of clean fine sand to silty fine sand. The tests on which these curves where based had been done with piles with a length-diameter ratio of approximately 34 (diameter $0.61 \mathrm{~m}$ and an embedded length of $21.03 \mathrm{~m}$ ). These tests were performed for both static and cyclic loadings at a frequency of approximately $0.06 \mathrm{~Hz}$, which corresponds to the quasi-static range of a typical bottom-founded offshore wind turbine.

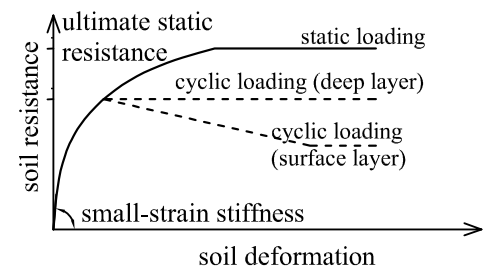

(a)

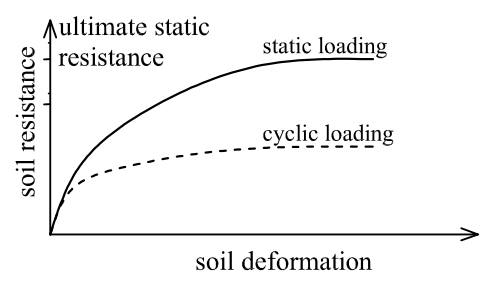

(b)

Figure 15. Representations of $p-y$ curves for (a) clay and (b) sand, distinguishing the soil-structure interaction for static or cyclic loading.

In conclusion, the $p-y$ curve method was developed for the modelling of large displacements of flexible piles, whereas monopile foundations for offshore wind turbines must be characterized as rigid (for diameters in the range of 4 to $6 \mathrm{~m}$, the length-diameter ratios are in the order of five to six [112]), for which the soil-structure interaction must be characterized differently (see Figure 16). Ref. [113] stated that with the application of the $p-y$ curve method, the stiffness of the foundation of an offshore wind turbine is underpredicted. Moreover, the studies resulting in the standardized force-displacement curves primary focussed on the soil reaction for large deformations. For the estimation of the fatigue damage accumulation in offshore wind support structures, the small-strain stiffness of the soil is of particular relevance (see Figure 15a). 


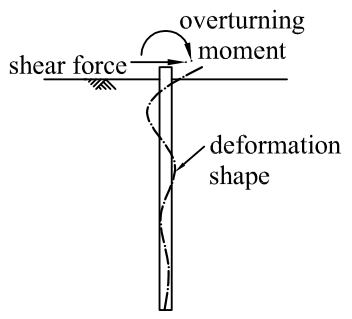

(a)

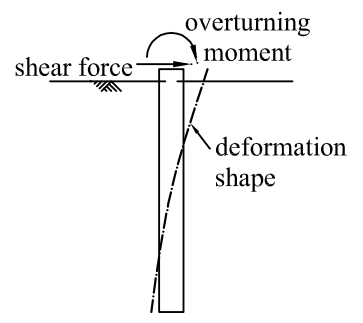

(b)

Figure 16. Schematic representation of the lateral pile deformation resulting from a shear force and overturning moment at the soil surface, distinguishing (a) a flexible pile and (b) a rigid pile.

For piles with a diameter larger than $1.0 \mathrm{~m}$, the design standard [13] requires the validation of the $p-y$ curve method with a finite-element analysis. In research, the small-strain stiffness of sand and clay for rigid piles has been investigated on the basis of the finite-element method, as well as small and full-scale experiments. Reference [37] used in situ measured small-strain shear moduli to develop a three-dimensional finite-element model of an embedded monopile to validate the soil stiffness predicted by the $p-y$ method. The predicted pile deflections with the three-dimensional model were smaller than the deflections predicted with the $p-y$ curve method. References [114,115] have proposed a modified initial stiffness for piles in sand, depending on the diameter, internal friction angle and the depth below the mudline.

Cyclic loading conditions allow for kinematic hardening and ratcheting —or cyclic creep-of non-cohesive soils, affecting the soil-structure interaction [116,117]. Reference [118] demonstrated the influence of soil conditions changing over time on the fatigue life-time of monopile foundations. For saturated and cohesive soils, cyclic loading may induce gapping and subsequent expulsion of water carrying soil particles. As a consequence, both the resistance and the stiffness of the soil reduce, even for relatively small deformations [108]. The behaviour of monopile foundations under lateral cyclic loading was investigated by [119], focussing specifically on cohesionless soil. The soil response is represented by a degradation stiffness model, which combines finite-element simulations of the pile-soil interaction and an evaluation of drained cyclic triaxial tests. The work established a relation between the pile performance under cyclic loading and its embedded length, and defines design criteria for large-diameter monopiles. Reference [120] suggested an increased soil stiffness for cyclic motions to account for the pore pressure generation in saturated soils. Reference [121] provided a historical review of empirical studies to the response of cyclically loaded piles. As yet, the principles behind the cyclic soil-structure interaction and the subsequent pile deformations are not fully understood [122], and the reliability of existing methods to estimate the long-term pile deflections and rotations at the mudline should be considered from that perspective [27].

Given the inconvenience of the standardized force-deflection curves for piles with a small diameter-length ratio, alternative modelling approaches are required for offshore wind applications. For design purposes, these alternative models need to be computationally efficient, rendering the three-dimensional finite-element approach undesirable. As a consequence, a need exists for simplified equivalent representations of the three-dimensional soil-structure interaction for rigid piles. Reference [123] published a survey, in which a selection of alternative methods for the modelling of soil-structure interaction is gathered and reviewed. The work focussed on both 1D idealizations and continuum models. Reference [124] suggested to replace the embedded monopile by a stiffness matrix at the mudline, to simplify the modelling of the foundation of offshore wind turbines, where the components of the stiffness matrix can be estimated with the Randolph's method. Reference [125] adopted a similar stiffness modelling, but neglected the coupling between translations and rotations. A similar approach was taken by [126], who investigated the dynamic characteristics of an offshore 
wind turbine model with stochastic $p-y$ curves. Other studies proposed a discretized foundation model for a monopile support structure, recognizing the relevance of the coupling between the translational and rotational motions. As an alternative, the application of an equivalent fixity depth was suggested $[127,128]$

References $[129,130]$ presented a procedure to define an effective one-dimensional Winkler foundation from a three-dimensional response obtained with a finite-element model. The effective foundation models capture the three-dimensional effects of the soil-structure interaction of piles with a large diameter compared to the embedded length-in other words, piles with a small length-diameter ratio. This method was extended further in [18], where global stiffness kernels were extracted from simulations with a three-dimensional inhomogeneous continuum. On the basis of these kernels-which can include soil stiffness, inertia and damping-a one-dimensional non-local Winkler foundation can be defined, with which the three-dimensional dynamic response of a 'vast range of soil-pile systems can be mimicked'. Reference [131] used a three-dimensional finite-element model to analyze the dynamic response of a wind turbine on a monopile foundation. This study particularly focussed on the effect of hydro-mechanical coupling on the cyclic soil response. In a second study, [132], uncoupled lateral and rotational springs were suggested to replace the three-dimensional soil-structure interaction.

The damping through the interaction between the structure and the soil exists through radiation and hysteresis. The former type of damping is considered irrelevant for the frequency range of interest for offshore wind applications, i.e., below $1 \mathrm{~Hz}$ [133-135]. Reference [135] defined a viscous damping representation for the lumped-parameter modelling of an offshore wind turbine, based on a two-dimensional finite-element representation including hysteretic damping. Reference [132] defined a viscous damper to replace the hysteretic dissipation of energy at the dominant frequency of oscillation.

While many studies on the modelling of the soil-structure interaction for offshore wind turbines have been done, no final substitution for the $p-y$ method has been defined yet. As to date, all alternatives require the modelling of a foundation in a three-dimensional continuum, from which the soil-structure interaction characteristics to be adopted for the modelling of the wind turbine foundation can be extracted. As suggested by [31], a re-evaluation of the $p-y$ curve method for pile sizes applicable in the offshore wind industry. The establishment of new curves requires full-scale and long-term measurements, to correctly account for the rigidity of the foundation structures, as well as the history-dependency of the soil properties under cyclic loading. For offshore wind foundations, the small-strain stiffness and the damping potential of the soil are of particular relevance.

For alternative foundation solutions, the application of the $p-y$ curve method is less disputed, or not considered at all. Multi-member support structures, such as so-called jackets and tripods are often founded on multiple flexible piles, for which the validity of the $p-y$ method is still assumed. In this respect, Ref. [43] illustrated the relevance of soil-structure interaction for a multi-member support structure, founded on multiple flexible piles. Concerning the soil-structure interaction, both lateral and axial springs were implemented, based on the $p-y$ method. Other foundation concepts involve gravity-based solutions and suction buckets. Regarding the modelling of gravity-based foundations, Ref. [133] investigated the lumped-parameter representation of the dynamic characteristics of homogeneous and layered soils. A three-dimensional finite-element model for a suction bucket foundation was presented by [136], whereas [137] presented a three-dimensional limit method for the stability analysis of suction buckets. The modelling of gravity-based and suction bucket foundations still require the definition of an applicable dynamic stiffness, accounting for cyclic degradation and liquefaction $[138,139]$. An increasing popularity of these alternative foundation concepts may instigate the need for industry-standard force-response relations as well.

\section{Code Comparison and Experimental Validation}

Models for offshore wind turbines, either integrated or decoupled, and including formulations for the different environment-structure interactions, predict responses to wind and wave excitations for 
which the structures are designed. The overview of the different approaches to model the interactions between the structure and the environment reveals that many uncertainties still exist. In this respect, a number of design tool comparison programmes have been executed over time [140-144].

Reference [30] presented a comparison of the capabilities of available design tools. Concerning the aerodynamic models, all considered tools employ the blade-element/momentum theory, whereas most allow for the implementation of dynamic stall. The linear wave theory in combination with Morison's equation is the standard model for the evaluation of wave loads. Some packages allow for the application of the stream function wave theory, and the linear potential flow theory for the implementation of diffraction and radiation is offered by few. The industry-standard structural modelling approach is the finite-element method or a multi-body dynamics formulation. For the future development of design tools, Ref. [30] suggested, among others, the validation of the hydrodynamic models for multi-member support structures, the implementation of non-linear blade deflection models, the coupling of the aerodynamic analyses with computational fluid dynamic approaches and the corresponding integration of the turbine within the context of the complete wind farm, and the development of a validated model for the prediction of ice loads.

A benchmark study regarding the comparison of software tools available for the integrated analysis of a $5 \mathrm{MW}$ offshore wind turbine was performed by [145]. A main finding was that the agreement between the estimated structural responses was quite good, differences resulting particularly from varying model fidelities and aerodynamic and hydrodynamic load implementations. References $[146,147]$ have performed a comparative study with the focus on the hydrodynamic load on a cylindrical structure, including the effect of a sloped seabed. The added value of fully non-linear potential flow analyses and computational fluid dynamics techniques for highly non-linear wave conditions was recognized. Furthermore, it was concluded that none of the tested codes was capable to capture the total force resulting from a breaking wave event. Concerning the existing design tools, Ref. [8] pointed out that only a few specialized software packages are available to evaluate the combined aerodynamic and hydrodynamic excitations of offshore wind turbines. Moreover, the functionality of these packages is often limited and customizations to perform non-standard simulations may not always be possible.

Validation by means of full-scale measurements of installed offshore wind turbines are required to further develop the modelling strategies for future turbines. Measurement campaigns on offshore wind turbines have aimed in particular at the identification of the fundamental natural frequencies, both in fore-aft and side-to-side directions and the estimation of the corresponding damping. Operational modal analysis based on assumed broadband ambient excitations, response measurements to rotor stop tests and the seismic testing of the soil are examples of applied identification strategies [37,148,149].

Regarding the natural frequencies of offshore wind turbines, many studies have addressed the identification of the natural frequencies used the results to calibrate a structural model $[134,148,150]$-of either onshore or offshore wind turbines-while addressing the reliability of different identification techniques. In the following, an overview is presented of studies that compare the natural frequencies predicted with a structural model with identified frequencies from measurements, as these validations can be used to address the validity of the modelling approach, and studies identifying the damping corresponding to the first modes of vibration. This overview is based on a chronological ordering of results related to specific measurement campaigns. Tables 2 and 3 present an overview of the natural frequency comparisons and the identified damping ratios.

Reference [124] performed a natural frequency validation, using the measured nacelle acceleration of operating wind turbines from two wind farms in the Netherlands for a comparison between predicted and identified first natural frequencies, and compared those with the predicted frequencies from a structural model. Whereas the predicted first natural frequencies at the wind farm Irene Vorrink slightly underestimated the identified natural frequencies, up to $5 \%$, the predicted natural frequencies at the wind farm Lely showed an underestimation of $9 \%$ and $37 \%$, respectively. An explanation for the difference at the Irene Vorrink farm was primarily found in the selection of the soil parameters and the modelling of the soil-structure interaction. A specific explanation for the large differences at the Lely wind form was not found, but it was expected to be due to erroneous inputs for the structural model. 
Even though not offshore, Ref. [148] focussed on the identified the damping ratios of an onshore pitch-regulated, variable speed $2.75 \mathrm{MW}$ turbine by means of pitch angle and generator torque variations and operational modal analysis based on stochastic sub-space identification. The most reliable results were obtained with the operational modal analysis, as with the pitch angle and generator torque variations, it turned out to be difficult to isolate the damping corresponding with the first fore-aft and side-to-side modes. Concerning the first fore-aft mode, damping ratios with an average of $12 \%$, with a standard deviation of $1.2 \%$, for a variation of wind speeds. The lateral damping varied from $7.9 \%$ at low wind speeds to $3.2 \%$ at higher wind speeds, a decrease which is explained by the increasing pitch angle of the blades. As the damping ratios were obtained from an operating turbine, the values include the high apparent damping from the aerodynamic interaction, on top of the structural and soil damping contributions.

Evaluating the measurement data of a series of consecutive rotor stop tests at the Burbo Banks wind farm, [149] identified a damping ratio of 3\% of the critical damping of the first fore-aft mode, $1.5 \%$ of which was believed to be generated by soil-structure interaction. The identified damping ratio is significantly lower than the value presented by [148], since the contribution of the aerodynamic damping is negligibly small in case of rotor stop tests.

Reference [151] identified the damping ratio for a monopile-based offshore wind turbine in the North Sea from a series of rotor stop tests. The obtained damping ratios were in the range from $2.2 \%$ to $2.4 \%$. An extended study was presented by [134], who considered both rotor stop tests and acceleration measurements of monopile-based wind turbines in five offshore wind parks, and focussed on the time dependency of the modal parameters and the identification of the side-to-side-or cross-wind-damping. The amount of soil damping was identified as 0.06 , in terms of the logarithmic decrement, which corresponds to a modal damping of approximately $1.0 \%$. The rotor stop tests resulted in an identified first fore-aft mode damping ratio from $2.4 \%$ to $2.5 \%$, whereas from measurements on operating turbines, an average side-to-side damping in the range of 2.5 to $2.9 \%$ was identified. It was suggested that the backfilling of the scour hole around the monopile foundation is the main source of the time dependency of the identified dynamic characteristics.

Concerning the fundamental natural frequencies, Ref. [120] reported values identified from rotor stops tests on $3 \mathrm{MW}$ turbines in the North Sea. The identified frequencies were significantly higher, in the range of 2 to $13 \%$, than the first natural frequencies obtained with a computational model, for which $p-y$ curves were applied. The observed deviations were attributed to the pore pressure build-up in dynamic soil-structure interaction of saturated soils. In this respect, Ref. [37] adopted the small-strain shear modulus from in-situ measurements to construct a three-dimensional soil-structure interaction of an offshore wind turbine. The model was used to estimate the static deflection of the wind turbine, which was compared with the deflection determined with the industry-standard $p-y$ curve method. The later was shown to predict up to $50 \%$ larger deflections at the mudline.

The experimental data from a measurement campaign in the Belgian North Sea was used by [152] to identify of the dynamic properties of a $3 \mathrm{MW}$ offshore wind turbine on a monopile foundation. The measurement data were obtained during rotor stops, as well as from idling turbines. The identified first natural frequencies were compared with the frequencies obtained from a numerical model. The identified first natural frequency from the rotor stop test was $4.5 \%$ lower than the predicted natural frequency, whereas for the idling turbine the identified frequency was $2.9 \%$ lower. The soil-structure interaction was accounted for by $p-y$ curves. Regarding the damping ratio of the first fore-aft mode, from both tests a ratios of $1.05 \%$ of the critical damping was identified. Reference [153] presented a comparative study on the different techniques for system identification with the same measurement data, identifying also a damping ratio of $1.27 \%$, corresponding to the first side-to-side mode. The higher side-to-side damping, compared to the fore-aft damping, was explained by the large blade pitch angle, resulting in a larger exposed blade area in the side-to-side direction. In a subsequent work, Ref. [154], presented the identification of the modal damping ratios from continuous measurements on an idling or parked wind turbine. Average damping ratios of $1.86 \%$ and $2.49 \%$, corresponding to the first fore-aft 
and side-to-side modes of vibrations, respectively, were identified. These values are higher than the identified damping in the previous studies $[152,153]$, as during these measurements a tuned-mass damper was active. The most extensive comparison was presented by [155], who compared the identified natural frequencies with frequencies predicted by a numerical model and presented the variation in damping ratios with the wind speed, both for parked conditions. In comparison with the natural frequencies estimated from time-simulations, the first fore-aft frequency provided a virtually perfect fit, whereas in the first side-to-side frequency was overestimated by $1.37 \%$. Again, $p-y$ curves were adopted to represent the soil-structure interaction. The mean identified damping ratio corresponding with the first fore-aft mode increased from $1.73 \%$ to $2.77 \%$ with increasing wind speed, whereas the mean first side-to-side damping ratio varied from $2.18 \%$ to $3.19 \%$ with the increasing wind speed, with the tuned-mass damper active, again showing a higher damping in the side-to-side direction die to the larger exposed blade area.

To validate the modelling of the soil-structure interaction specifically, Ref. [156] presented the results of vibration measurements of an in-situ monopile foundation in a near-shore wind farm, with a stiff sandy soil composition. From the pile-only measurements, the identified low-frequency soil stiffness was $140 \%$ higher than the stiffness prescribed by the $p-y$ curve method. With the application of the identified soil stiffness in the numerical model, using a one-dimensional effective stiffness [130], a good prediction of the identified fundamental natural frequency was obtained.

A comparison of the measured response of a North Sea wind turbine to models with different representations of the soil-structure interaction was presented by [157], including $p-y$ curves and a macro-element representation. In comparing the identified first fore-aft and side-to-side natural frequencies with the predicted frequencies from a model with $p-y$ curves, the predictions underestimated the actual natural frequencies by $12.3 \%$ and $12.8 \%$, respectively. These differences confirm the findings of $[120,156]$, who illustrated the weak representation of the industry-standard $p-y$ curves for monopile-based support structures of offshore wind turbines too.

When considering the different natural frequency comparisons, listed in Table 2, the importance of adequate modelling of the soil-structure interaction must be recognized. This relates to a correct representation of the small-strain stiffness, the cyclic degradation and the selection of the applicable sea bed level, as for non-cohesive soils and in absence of adequate scour protection a variation in soil level and compaction at the mudline is to be expected [158,159]. Other sources of modelling inaccuracy may exist in the shape of the representation of the rotor-nacelle assembly and the mass distribution of the transition piece and the electrical equipment. These components, however, were not present in the full-scale experiments of [156], leaving the hydrodynamic added mass as the only other source of modelling inaccuracy, next to the representation of the soil-structure interaction.

Table 2. Overview of studies presenting validations the first fore-aft and side-to-side natural frequencies of wind turbines, indicating the underestimation of the modelled frequencies compared to the identified frequencies.

\begin{tabular}{llccl}
\hline Study & Turbine & Fore-Aft & Side-to-Side & Operational State \\
\hline$[124]$ & Irene Vorrink wind farm & up to 5\% & - & power production \\
& Lely wind farm & 9 to 37\% & - & power production \\
{$[120]$} & North Sea 3MW turbines & 2 to $13 \%$ & - & rotor stop \\
{$[152]$} & North Sea 3MW turbine & $-4.5 \%$ & - & rotor stop \\
& & $-2.9 \%$ & - & idling \\
{$[155]$} & North Sea 3MW turbine & $0.00 \%$ & $-1.37 \%$ & parked \\
{$[157]$} & North Sea turbine & $12.3 \%$ & $12.8 \%$ & idling \\
\hline
\end{tabular}

Regarding the identified damping ratios, Table 3, it becomes clear that fore-aft damping values for operating conditions are lacking. The only exception are the results presented by [148], which were obtained from an onshore turbine. These results give an insight in the high potential of the aerodynamic damping. The reported damping values from rotor stop tests and for parked-idling turbines are all 
within the same range of magnitude. These values can be expected to represent the structural damping, as well as the damping from the soil-structure interaction. In this respect, the identified side-to-side damping is slightly higher than fore-aft damping, as for non-operating conditions the wind turbine blades provide a larger lateral resistance.

Table 3. Overview of studies presenting validations the first fore-aft and side-to-side damping ratios of wind turbines.

\begin{tabular}{llccl}
\hline Study & Turbine & Fore-Aft & Side-to-Side & Operational State \\
\hline$[148]$ & $\begin{array}{l}\text { 2.75MW turbine } \\
\text { (onshore) }\end{array}$ & $12 \%$ & 3.2 to $7.9 \%$ & power production \\
{$[149]$} & Burbo Banks & $3 \%$ & - & rotor stop \\
{$[151]$} & North Sea wind turbine & 2.2 to $2.4 \%$ & - & $\begin{array}{l}\text { rotor stop } \\
\text { rotor stop }\end{array}$ \\
{$[134]$} & North Sea wind farms & 2.4 to $2.5 \%$ & - & power production \\
& & - & 2.5 to $2.9 \%$ & rotor stop \\
{$[152]$} & North Sea 3MW turbine & $1.05 \%$ & - & idling \\
& & $1.05 \%$ & - & idling \\
{$[153]$} & North Sea 3MW turbine & $1.05 \%$ & $1.27 \%$ & parked/idling \\
{$[154]$} & North Sea 3MW turbine & $1.86 \%$ & $2.49 \%$ & parked \\
\hline 155$]$ & North Sea 3MW turbine & 1.73 to $2.77 \%$ & 2.18 to 3.19\% & park \\
\hline
\end{tabular}

\section{Solution Approaches}

In Section 3 of this work, the existing approaches to model the environmental interactions with offshore wind support structures were considered. An overview of different code comparison studies, as well as experimental validations, was presented in Section 4 to give an impression of the validity of the modelling strategies. Apart from different approaches to modelling the structure, different approaches to predict the response to environmental excitations exist, with the aim of generating sufficiently accurate results, against as low as possible computational costs. In this respect, three approaches are distinguished here:

- Reduction of the total number of coupled differential equations that need to be solved.

- Reduction of the required number of load cases that need to be analysed.

- Reduction of the complexity of the numerical operations, i.e., transforming the system of equations to the frequency domain.

A finite-element formulation of an offshore wind support structure including the environmentstructure interactions generally consists of a large number of coupled second-order differential equations. As a consequence of the non-linear nature of the system, the structural response to wind and wave excitations is commonly estimated by means of time-domain simulations. With the application of a Galerkin reduction [160], the number of equations that require simultaneous solving can be kept within 'reasonable' limits. Within the iterative solution procedure, resulting from the decoupled modelling approach, dynamic sub-structuring techniques allow for the separate analysis of structural components, and the subsequent assembly of reduced component models. These techniques aim at capturing the most relevant dynamic characteristics of a structural component, and, subsequently, analyzing the structure as a whole [161].

Instead of reducing the number of degrees of freedom, it has been attempted to reduce the number of required simulations, mainly resulting from the analysis of the fatigue limit state [162]. Other researchers aimed at defining the dynamic system in terms of a system of algebraic equations, by transforming a reduced-order model to the frequency domain [163]. To circumvent the non-linear aero-elastic interaction of the rotor, $[65,164]$ suggested a hybrid time-frequency domain approach. 


\subsection{Dynamic Sub-Structuring}

Instead of employing the full structural matrices of the foundation structure for the aerodynamic analysis, with the application of a model reduction technique a set of reduced structural matrices-or 'super elements' - can be extracted, which can subsequently be applied as boundary conditions for the turbine model. Figure 17 presents a schematization of this technique for offshore wind turbines. Concerning these reduction techniques, which are generally referred to as dynamic sub-structuring, the Guyan reduction represents the foundation structure only quasi-statically, whereas the Craig-Bampton technique accounts for both the static condensation and the fixed- or free-interface dynamic response, allowing for a reduced-order model, which includes the dynamic characteristics relevant for the required simulations [165]. Impulse-based techniques employ a set of Green's functions to represent a structural component in a reduced manner for the analysis of the complete system [166,167].

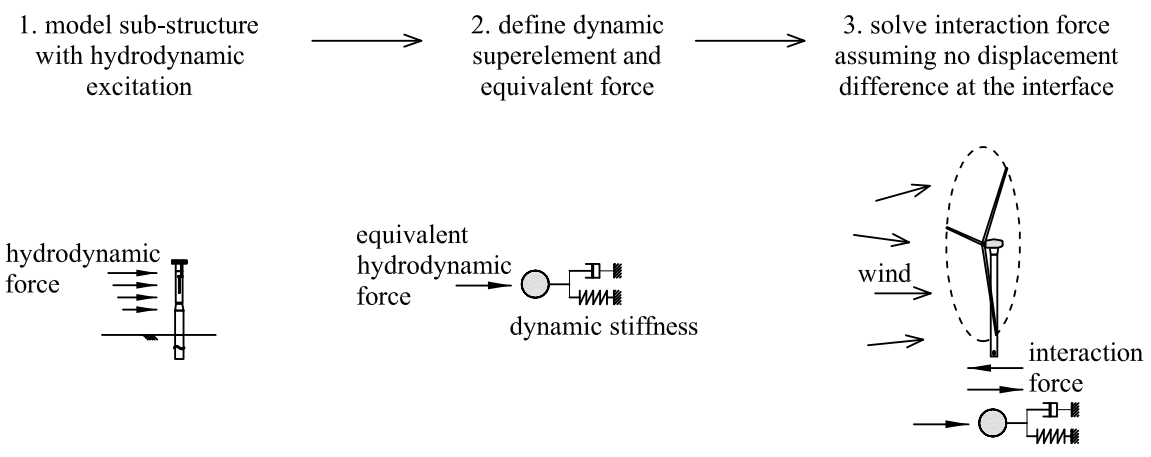

Figure 17. Schematization of the dynamic sub-structuring technique for offshore wind turbines [161].

The equations of motion of the reduced system based on the Craig-Bampton technique are coupled, since the adopted modes of vibration are not orthogonal. The selection of the modal basis requires a convergence analysis, to ensure a sufficiently accurate dynamic representation of the system. In case too few dynamic modes are selected, the reduced model does not capture the 'real' resonance frequencies of the system. Although the Craig-Bampton technique primarily aims at the spectral convergence of the modal basis, without spatial convergence-required for the forced-response analysis of a dynamic system - a sufficient accuracy of the reduced-order model is not guaranteed. With the inclusion of a set of modal truncation vectors - or load-dependent residual vectors-the modal basis can be augmented and the estimation of the forced dynamic response can be improved, a method referred to as the Augmented Craig-Bampton technique [161]. Alternatively, the forces acting on a sub-structured component can be represented by equivalent forces acting on the interfaces between the structural components. The concept of blocked forces and equivalent free-interface displacements was originally developed for the frequency domain, and extended by [29] to applications in the time domain.

The benefits of the reduced-order modelling are enlarged for foundation structures consisting of multiple members, such as space-frame structures, which require a large number of structural degrees of freedom for accurate modelling. The sub-structuring technique finds its basis in the principle of linear superposition, implying that a super element represents a linearized projection of the foundation structure. Given the non-linear nature of both the hydrodynamic interaction and the soil-structure interaction, different load cases may require the derivation of different super elements. Moreover, the non-linear aero-elastic coupling possibly requires an enhanced modal basis for the derivation of the super element, since higher-order modes may contribute to the dynamic response of the system too.

The commercially available simulation tool BLADED (Within the context of this work, reference is made to BLADED 4.6.) employs a sub-structuring technique to simulate the response of an offshore wind turbine to environmental excitations. The reduced-order modelling is based on the static deformation shapes and the fixed-interface modes of vibration. In this respect, an important point of 
attention relates to the natural frequency convergence of the applied component-mode synthesis with the number of estimated modes. The preliminary design of a support structure structure is commonly based on a frequency analysis, which aims at the estimation of the natural frequencies to avoid interference of the natural frequencies with the rotor and blade-passing frequencies. The accuracy of the estimated frequencies may be low if only few estimated modes are included.

\subsection{Load Cases Reduction}

Apart from the efforts to reduce the complexity of the required simulations for the design of an offshore wind support structure-concerning both the non-linear environment-structure interactions and the number of degrees of freedom-a reduction of the vast amount of simulations that need assessment would allow for a speed-up of the entire analysis of an offshore wind support structure. Concerning the analysis of the ultimate limit state, Ref. [14] considered the relevance of the load cases for power production and parked conditions. The design load case combining power production with severe wave conditions was found to be design driving, with respect to the maximum overturning moment at the mudline.

The analysis of the fatigue limit state demands a joint-probability distribution of the wind and wave states at the location under consideration, providing stationary Gaussian descriptions of the occurring environmental conditions. In a practical situation, long-term measurement of combined wind speeds, significant wave heights and wave periods-zero-upcrossing, zero-downcrossing or peak-as well as directionality data should be available. The assessment of the expected fatigue damage entails the evaluation of this joint-probability distribution with sufficiently small bin sizes, having the number of simulations grow to several tens of thousands easily.

Reference [65] introduced the concept of load case lumping to the field of offshore wind turbines. Establishment of the sets of wind and wave conditions, which together define the lumped load case, is initially based on some rules of proportionality, which relate the separate environmental conditions to an expected fatigue damage. From a comparison with the damage resulting from the elementary load cases, the lumped load cases can be refined. As the operational state of the wind turbine depends on the governing wind conditions, the distribution of sea states is often considered for a given wind state, assuming that the system properties are independent of the stochastic wave conditions. On this basis, the objective is to find a single equivalent sea state that predicts a damage similar to the full set of states from the probability distribution.

Reference [168] considered the lumping of wave conditions, based on a frequency-domain analysis of the wave-induced fatigue damage of monopile support structures. Provided a low damping ratio, which de facto limits the method to non-operating turbines, an equivalent spectral density of the wave elevation is obtained from the spectral densities of a set of sea states at the first natural frequency of the offshore wind turbine. The suggested method accounts for the first mode of vibration only and is invalid for drag-dominated wave conditions.

The lumped load cases obtained in accordance with $[65,168]$ may not imply damage equivalency at different locations critical for the fatigue assessment. In this regard, Ref. [169] suggested to determine the damage contour lines for two well-separated locations and to select the damage equivalent wave conditions for associated wind conditions from the intersection point of both lines. Reference [162] presented a more extensive comparison of the different lumping methods.

Another line of research focussed on the identification of the load cases with the largest contribution to the damage accumulation. Neglecting the contribution of the structural response, [5] defined a fatigue damage parameter to quantify the contribution of different sea states to the fatigue development. Focussing on a jacked-based wind turbine, Ref. [15] addressed the reduction of the set of load cases based on statistical evaluations. The work shows that reduced set can produce results which are comparable to those of the complete set. Moreover, it was discovered that the introduced uncertainty grows at a lower rate than the dimension reduction of the set. Reference [170] showed that a small set of the most severe fatigue design load cases for a particular turbine suffice for an 
accurate prediction of the fatigue damage of a slightly different design, for instance for a related or optimized design.

An accurate prediction of the fatigue damage requires a sufficiently long simulation of the environmental conditions, exceeding the commonly adopted $6 \times 10 \mathrm{~min}$ [171], as well as a stochastic distribution of the sea state parameters within a considered wind speed bin [172]. This recommendations are more relevant for the more severe load cases than for the milder conditions. Based on this idea, Ref. [173] introduced different load case reduction concepts, using Monte Carlo simulations, basing the number of simulations on either the probability of occurrence, the expected damage or the equivalence of load conditions. The sampling approaches proposed by [173] were validated by [174] on the basis of an extensive data set from the Northwind wind farm. The study demonstrated an improved performance compared to standard sampling methods. Nevertheless, it is concluded that the uncertainty in life-time prediction remains high, depending significantly on the design of the offshore wind turbine and controller actions. A summary of the different approaches to reduce the number of load cases is given by Table 4 .

Table 4. Overview of studies presenting approaches to reduce the number of environmental load cases.

\begin{tabular}{lll}
\hline Study & Approach & Comment \\
\hline$[65]$ & $\begin{array}{l}\text { sea-state lumping based on damage-equivalence } \\
\text { sea-state lumping based on wave spectral density } \\
\text { at the first natural frequency } \\
\text { sea-state parameters from damage-contour } \\
\text { lines ensuring simultaneous compliance with } \\
\text { damage equivalency criteria at different locations } \\
\text { fatigue damage parameter for different sea states } \\
\text { exclusion of load cases with non-critical directionality } \\
\text { and/or low probability of occurrence } \\
\text { variable wind speed bin sizes }\end{array}$ & $\begin{array}{l}\text { no dynamic interaction } \\
\text { only non-operating } \\
\text { turbines } \\
\text { damage-contour lines are } \\
\text { obtained from many } \\
\text { simulations } \\
\text { no dynamic interaction } \\
\text { pre-knowledge required } \\
\text { on structural response } \\
\text { expert knowledge to } \\
\text { define bin sizes required }\end{array}$ \\
\hline [15] & * this study focusses on jacket-based support structures.
\end{tabular}

In conclusion, it has been demonstrated that the accumulated fatigue damage can be approximated with a limited set of load cases only. Regarding the selection of these load cases, the required simulation time and the definition of the environmental conditions-either deterministically of stochasticallyremains a topic of ongoing research. Approaches that select the load cases based on the relation between the expected damage and the operational state seem to be most promising for practical applications.

\subsection{Frequency-Domain Analysis}

Instead of aiming to reduce the sheer amount of required simulations for the design of an offshore wind support structure, the simulation time of each single realization could virtually be nullified if the system allowed for analysis in the frequency domain. This approach has found its application in the analysis of offshore structures for oil and gas applications [90], for which the main environmental excitations are of hydrodynamic nature. In this respect, the drag force dependency on the relative velocity is non-linear, introducing both linear and non-linear interaction terms to the model of the offshore wind support structure (provided that the drag contribution is governing, which only applies to high/long waves, relative to the structural diameter). With the purpose of analyses in the frequency domain, Ref. [175-177] presented spectral densities of the drag force on rigid structures. Attempts to assess the response to the non-linear drag force on compliant structures in the frequency domain have been done by [178-181], who employed the Volterra series expansion technique.

Concerning the aerodynamic excitation of the turbine rotor, Ref. [163] attempted to derive the frequency-response function between a homogeneous turbulent inflow field and the forcing acting on the tower top. Reference [65], however, concluded that the frequency-domain approach wind turbines 
is inapplicable, first of all because of the non-linear aero-elasticity. Besides, the considerable geometrical non-linearity, mainly resulting from the flexibility of the rotor blades, renders the frequency-domain approach unsuitable too. Moreover, a transfer function between the inflow and the tower top excitation does not capture the transience resulting from varying operational conditions.

As an alternative, Ref. [65] introduced a hybrid time-frequency domain approach, in which the aerodynamic interaction is assessed in the time domain and the hydrodynamic excitation in the frequency domain, while accounting for the present aerodynamic damping. This approach is illustrated by Figure 18. For the analysis of the fatigue limit state, the fatigue damages from the separate analyses were combined by means of a quadratic superposition procedure. Reference [164] used time-domain simulations for the aerodynamic analysis as well, employing a model of a flexible rotor mounted on a rigid tower. The power spectral density of the resulting tower top forces was subsequently used for a frequency-domain analysis of the support structure, combined with a spectral definition of a corresponding sea state. The aerodynamic interaction was accounted for by an additional modal damping. This hybrid time-frequency domain approach circumvents the difficulties arising from the non-linear aerodynamic interaction and the control system. Besides the auto-spectra of the wind and wave excitations, however, this approach requires a cross-spectral input as well.
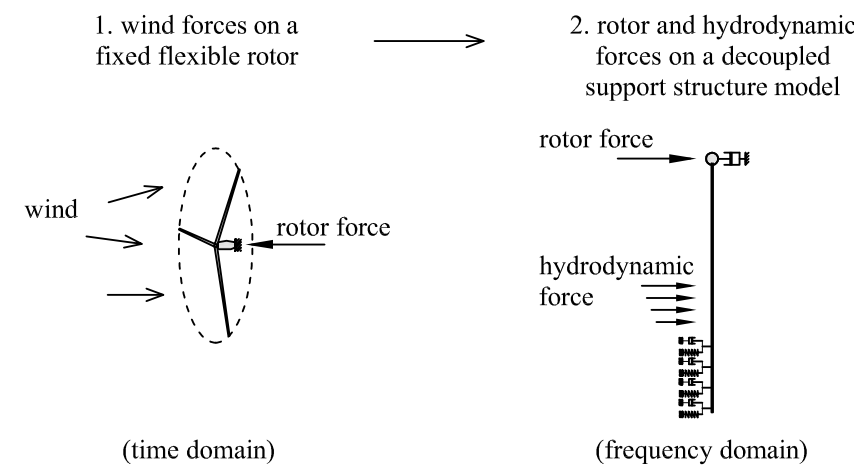

Figure 18. Schematization of the hybrid analysis by [65]. Regarding the properties of the decoupled model, reference is made to Figure 4.

\section{Conclusions}

This paper provided an overview of the existing modelling strategies for the decoupled analysis of offshore wind support structures, with a primary focus on monopile-based wind turbines. Contrarily to an integrated design approach, the decoupling concerns first and for all the separate analysis of the foundation on the one hand and the turbine on the other, leaving the interface forces as the main content of the communication between the turbine manufacturer and the foundation designer. In addition, however, also the decoupling of the foundation structure from the remaining surrounding media-water and soil-is a common strategy in the engineering practice, particularly in the preliminary design stage.

Section 2 of this work considered the design procedure and the main challenges in the design of offshore wind support structures. Recognizing the aim of reducing the total required computational time, while ensuring sufficient accuracy, the most important challenges are identified as follows:

- The design of offshore wind turbines is done in a sequential manner, requiring multiple iterations for optimized designs.

- Given the non-linear dynamic interactions between the structure and the environment, and the stochastic nature of the environmental excitations, a large number of time-domain analyses is required to predict the governing stress distribution and the accumulation of the fatigue damage.

- The available tools to model for commercial applications do not account for the environmentstructure interactions in full, whereas these tools do not allow for 'quick-and-dirty' preliminary designs either. 
- Measurement campaigns, of which the results are publicly available, reveal a discrepancy between the identified and the modelled dynamic properties, while the real accumulation of the fatigue damage in the structure is not yet fully understood.

With the exception of the lack of measurement data, the further development of decoupled modelling approaches, which primarily concerns the representation of the apparent dynamic characteristics of the different environmental excitations—wind, waves, soil—addresses these identified challenges. Regarding the strategies to decouple the different environment-structure interactions, an overview of which is provided in Section 3, several remaining challenges were identified, which can be summarized as follows:

- Currently, no full closed-form expressions for the aerodynamic damping of the operating turbine rotor are available. These expressions should describe the interaction in 3D and explicitly account for varying operational conditions. The validity of the involved linearization should be assessed, and possibly higher-order contributions should be considered as well, despite the loss of computational efficiency. The resulting damping matrix would serve the correct implementation of the aerodynamic damping properties for the different modes of vibration, contrarily to the application of a single damping ratio for each included mode.

- Impact loads from breaking waves require a description in terms of time-history and statistical characteristics. Moreover, a useful concept for non-linear irregular waves needs to be developed. Larger and novel foundation concepts require a mid-fidelity modelling approach for the hydrodynamic interaction.

- The increased relevance of loads from floating ice requires a model that accounts for the two-dimensional motion of the turbine structure with respect to the moving ice sheet. Moreover, the definition of so-called ice states, representing the long-term statistics of the occurring ice conditions, is a necessity for the analysis of both the ultimate and fatigue limits states of offshore wind turbines.

- Regarding the soil-structure interaction of monopile-based offshore wind turbines, the $p-y$ curve method requires re-evaluation, possibly resulting in the establishment of new curves, which should account for the rigidity of the structure and the history-dependency of the soil properties. Otherwise, an agreement should be reached on the applicable approach to obtain a one-dimensional description of the soil-structure interaction, obtained from three-dimensional analyses. In all this, the particular relevance of the small-strain stiffness and the damping of the soil should be recognized.

- With the development of alternative foundation concepts, such as gravity-based structures and suction buckets, industry-standard force-response relations defining the applicable dynamicstiffness and accounting for cyclic degradation and liquefaction still require development.

A small number of published experimental validations, presented in Section 4 confirms the relevance of the correct implementation of both the aerodynamic damping and the soil-structure interaction. In this respect, it should be highlighted, however, that more results of full-scale measurements are a necessity, to guide ongoing research in the right direction and to validate the new modelling approaches that will be proposed.

After modelling the offshore wind support structure with the applicable representation of the environment-structure interactions, a vast amount of load cases needs to be assessed. If physical and geometrical non-linearities are accounted for, the simulation of these load cases should in principle be performed in the time domain. In order to reduce the computational costs, while still generating sufficiently accurate results, the following approaches were considered in Section 5:

- Reduction of the total number of coupled differential equations by means of dynamic sub-structuring, which de facto represents a further decoupling of the system. The application of so-called super elements is most beneficial for support structures that require a large number 
of degrees of freedom. The non-linear nature of both the hydrodynamic interaction and the soil-structure interaction may require the derivation of specific super elements for different load cases. Moreover, the non-linear aeroelastic coupling may still require a large modal basis, to account for higher-order dynamic response contributions.

- Reduction of the required number of load cases that need to be analysed, by means of load case lumping and load case selection. Approaches that select the load cases based on the relation between the expected damage and the operational state seem to be most promising for practical applications.

- Reduction of the complexity of the numerical operations, by means of a frequency-domain analysis, which converts differential equations into algebraic equations. The analysis in the frequency domain, however, is restricted to the linear regime, rendering this approach in principle invalid for offshore wind turbines. A possible intermediate approach may be a hybrid solution, which considers the aerodynamic load on a fixed rotor in the time domain, after which the decoupled analysis of the support structure is performed in the frequency domain.

The identified challenges presented in this paper indicate that further improvements of decoupled modelling approaches for environment-structure interactions are possible and that such improvements could either reduce the computational costs required for the design of offshore wind support structures, or increase the accuracy with with the structural response to environmental actions can be prediction. These improvements are of particular relevance for the preliminary design stage, during which the need for quick assessments of structural variations or optimizations exists. The further development of the different modelling strategies, however, requires a continuous consideration of the trade-off between the computational costs and the accuracy of the modelling approach.

Author Contributions: P.v.d.M., M.V.; writing—original draft preparation, P.v.d.M.; writing—review and editing, K.N.v.D.; supervision. All authors have read and agreed to the published version of the manuscript.

Funding: This research received no external funding.

Acknowledgments: The author would like to thank their colleagues, Hayo Hendrikse and João de Oliveira Barbosa, for their thorough review of the manuscript and their valuable suggestions for improvement of the content.

Conflicts of Interest: The authors declare no conflict of interest.

\section{References}

1. Barroso, J.M. Europe 2020: A European Strategy for Smart, Sustainable and Inclusive Growth. European Commission, COM (3.3. 2010); 2010. Available online: https:/ / eur-lex.europa.eu/legal-content/en/ALL/ ?uri=CELEX:52010DC2020 (accessed on 22 September 2020).

2. WindEurope. Offshore Wind in Europe - Key Trends and Statistics 2019; Technical Report; WindEurope: Brussels, Belgium, 2020.

3. Lacal-Arántegui, R.; Yusta, J.M.; Domínguez-Navarro, J.A. Offshore wind installation: Analysing the evidence behind improvements in installation time. Renew. Sustain. Energy Rev. 2018, 92, 133-145. [CrossRef]

4. Tsouvalas, A. Underwater Noise Emission Due to Offshore Pile Installation: A Review. Energies 2020, 13, 3037. [CrossRef]

5. Velarde, J.; Bachynski, E.E. Design and fatigue analysis of monopile foundations to support the DTU $10 \mathrm{MW}$ offshore wind turbine. Energy Procedia 2017, 137, 3-13. [CrossRef]

6. Wu, X.; Hu, Y.; Li, Y.; Yang, J.; Duan, L.; Wang, T.; Adcock, T.; Jiang, Z.; Gao, Z.; Lin, Z.; et al. Foundations of offshore wind turbines: A review. Renew. Sustain. Energy Rev. 2019, 104, 379-393. [CrossRef]

7. Vergassola, M.; Cabboi, A.; van der Male, P. Offshore support structure concepts comparison for a $14 \mathrm{MW}$ two-bladed downwind wind turbine. J. Phys. Conf. Ser. 2020, 1618, 052076. [CrossRef]

8. Muskulus, M.; Schafhirt, S. Design optimization of wind turbine support structures-A review. J. Ocean Wind Energy 2014, 1, 12-22.

9. Chehouri, A.; Younes, R.; Ilinca, A.; Perron, J. Review of performance optimization techniques applied to wind turbines. Appl. Energy 2015, 142, 361-388. [CrossRef] 
10. Njiri, J.G.; Söffker, D. State-of-the-art in wind turbine control: Trends and challenges. Renew. Sustain. Energy Rev. 2016, 60, 377-393. [CrossRef]

11. Menezes, E.J.N.; Araújo, A.M.; da Silva, N.S.B. A review on wind turbine control and its associated methods. J. Clean. Prod. 2018, 174, 945-953. [CrossRef]

12. Mulders, S.P.; Zaaijer, M.B.; Bos, R.; van Wingerden, J.W. Wind turbine control: Open-source software for control education, standardization and compilation. J. Phys. Conf. Ser. 2020, 1452, 012010. [CrossRef]

13. DNVGL-ST-0126. Support Structures for Wind Turbines; Technical Report; DNVGL: Oslo, Norway, 2016.

14. Morató, A.; Sriramula, S.; Krishnan, N.; Nichols, J. Ultimate loads and response analysis of a monopile supported offshore wind turbine using fully coupled simulation. Renew. Energy 2017, 101, 126-143. [CrossRef]

15. Häfele, J.; Hübler, C.; Gebhardt, C.G.; Rolfes, R. A comprehensive fatigue load set reduction study for offshore wind turbines with jacket substructures. Renew. Energy 2018, 118, 99-112. [CrossRef]

16. Ong, M.C.; Bachynski, E.E.; Økland, O.D. Dynamic Responses of Jacket-Type Offshore Wind Turbines Using Decoupled and Coupled Models. J. Offshore Mech. Arct. Eng. 2017, 139, 041901.

17. Schafhirt, S.; Muskulus, M. Decoupled simulations of offshore wind turbines with reduced rotor loads and aerodynamic damping. Wind Energy Sci. 2018, 3, 25-41. [CrossRef]

18. Versteijlen, W.G.; de Oliveira Barbosa, J.M.; van Dalen, K.N.; Metrikine, A.V. Dynamic soil stiffness for foundation piles: Capturing 3D continuum effects in an effective, non-local 1D model. Int. J. Solids Struct. 2017, 134, 272-282. [CrossRef]

19. Hendrikse, H.; Nord, T.S. Dynamic response of an offshore structure interacting with an ice floe failing in crushing. Mar. Struct. 2019, 65, 271-290. [CrossRef]

20. Sánchez, S.; López-Gutiérrez, J.S.; Negro, V.; Esteban, M.D. Foundations in offshore wind farms: Evolution, characteristics and range of use. Analysis of main dimensional parameters in monopile foundations. J. Mar. Sci. Eng. 2019, 7, 441. [CrossRef]

21. Seidel, M. Design of support structures for offshore wind turbines-Interfaces between project owner, turbine manufacturer, authorities and designer. Stahlbau 2010, 79, 631-636. [CrossRef]

22. Seidel, M.; Voormeeren, S.; Van der Steen, J.B. State-of-the-art design processes for offshore wind turbine support structures. Stahlbau 2016, 85, 583-590. [CrossRef]

23. van der Tempel, J.; Molenaar, D.P. Wind turbine structural dynamics-a review of the principles for modern power generation, onshore and offshore. Wind Eng. 2002, 26, 211-222. [CrossRef]

24. Adhikari, S.; Bhattacharya, S. Dynamic analysis of wind turbine towers on flexible foundations. Shock Vib. 2012, 19, 37-56. [CrossRef]

25. Zania, V. Natural vibration frequency and damping of slender structures founded on monopiles. Soil Dyn. Earthq. Eng. 2014, 59, 8-20. [CrossRef]

26. Arany, L.; Bhattacharya, S.; Macdonald, J.H.G.; Hogan, S.J. Closed form solution of Eigen frequency of monopile supported offshore wind turbines in deeper waters incorporating stiffness of substructure and SSI. Soil Dyn. Earthq. Eng. 2016, 83, 18-32. [CrossRef]

27. Arany, L.; Bhattacharya, S.; Macdonald, J.; Hogan, S.J. Design of monopiles for offshore wind turbines in 10 steps. Soil Dyn. Earthq. Eng. 2017, 92, 126-152. [CrossRef]

28. Passon, P.; Branner, K. Load calculation methods for offshore wind turbine foundations. Ships Offshore Struct. 2014, 9, 433-449. [CrossRef]

29. Van der Valk, P.L.C.; Rixen, D.J. Substituting Internal Forces for Blocked Forces or Free Interface Displacements in Substructured Simulations. In Topics in Experimental Dynamic Substructuring; Springer: New York, NY, USA, 2014; Volume 2, pp. 77-96.

30. Vorpahl, F.; Schwarze, H.; Fischer, T.; Seidel, M.; Jonkman, J. Offshore wind turbine environment, loads, simulation, and design. Wiley Interdiscip. Rev. Energy Environ. 2013, 2, 548-570. [CrossRef]

31. Van Kuik, G.A.M.; Peinke, J.; Nijssen, R.; Lekou, D.; Mann, J.; Sørensen, J.N.; Ferreira, C.; van Wingerden, J.W.; Schlipf, D.; Gebraad, P.; et al. Long-term research challenges in wind energy-A research agenda by the European Academy of Wind Energy. Wind Energy Sci. 2016, 1, 1-39. [CrossRef]

32. DNVGL-ST-0437. Loads and Site Conditions for Wind Turbines; Technical Report; DNVGL: Oslo, Norway, 2016.

33. Van der Male, P.; Lourens, E. Operational vibration-based response estimation for offshore wind lattice structures. Structural Health Monitoring and Damage Detection. In Proceedings of the 33rd IMAC, A Conference and Exposition on Structural Dynamics; Springer International Publishing: Orlando, FL, USA 2015; Volume 7. 
34. Li, Y.; Castro, A.M.; Sinokrot, T.; Prescott, W.; Carrica, P.M. Coupled multi-body dynamics and CFD for wind turbine simulation including explicit wind turbulence. Renew. Energy 2015, 76, 338-361. [CrossRef]

35. Schløer, S.; Paulsen, B.T.; Bredmose, H. Application of CFD based wave loads in aeroelastic calculations. In Proceedings of the ASME 2014 33rd International Conference on Ocean, Offshore and Arctic Engineering, San Francisco, CA, USA, 8-13 June 2014; p. V09BT09A056.

36. Devolder, B.; Rauwoens, P.; Troch, P. Application of a buoyancy-modified k- $\omega$ SST turbulence model to

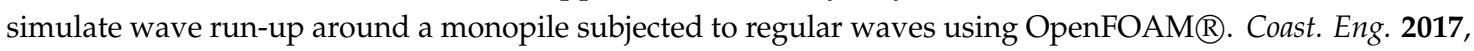
125, 81-94. [CrossRef]

37. Versteijlen, W.G.; van Dalen, K.N.; Metrikine, A.V.; Hamre, L. Assessing the small-strain soil stiffness for offshore wind turbines based on in situ seismic measurements. J. Phys. Conf. Ser. 2014, 524. [CrossRef]

38. Kementzetzidis, E.; Corciulo, S.; Versteijlen, W.G.; Pisanó, F. Geotechnical aspects of offshore wind turbine dynamics from 3D non-linear soil-structure simulations. Soil Dyn. Earthq. Eng. 2019, 120, 181-199. [CrossRef]

39. Seidel, M.; Von Mutius, M.; Rix, P.; Steudel, D. Integrated analysis of wind and wave loading for complex support structures of Offshore Wind Turbines. In Proceedings of the Conference Proceedings Offshore Wind 2005, Copenhagen, Denmark, 26-28 October 2005.

40. Kaufer, D.; Cosack, N.; Böker, C.; Seidel, M.; Kühn, M. Integrated analysis of the dynamics of offshore wind turbines with arbitrary support structures. In Proceedings of the European Wind Energy Conference, Marseille, France, 16-19 March 2009.

41. Jonkman, J.; Buhl M.L., Jr. FAST User's Guide. In Technical Report NREL/EL-500-38230; National Renewable Energy Laboratory: Golden, CO, USA, 2005.

42. Van der Male, P. Preliminary Design of Offshore Wind Turbine Support Structures-The Importance of Proper Mode Shape Estimation. In Proceedings of the EWEA Conference 2013, Vienna, Austria, 4-7 February 2013.

43. Abhinav, K.A.; Saha, N. Coupled hydrodynamic and geotechnical analysis of jacket offshore wind turbine. Soil Dyn. Earthq. Eng. 2015, 73, 66-79. [CrossRef]

44. Bisoi, S.; Haldar, S. Design of monopile supported offshore wind turbine in clay considering dynamic soil-structure interaction. Soil Dyn. Earthq. Eng. 2015, 73, 103-117. [CrossRef]

45. Jarquin Laguna, A. Modeling and analysis of an offshore wind turbine with fluid power transmission for centralized electricity generation. J. Comput. Nonlinear Dyn. 2015, 10, 041002. [CrossRef]

46. Bossanyi, E.A. The design of closed loop controllers for wind turbines. Wind Energy 2000, 149-163. [CrossRef]

47. Hansen, M.H.; Hansen, A.D.; Larsen, T.J.; Øye, S.; Sørensen, P.; Fuglsang, P. Control Design for a Pitch-Regulated, Variable Speed Wind Turbine; Technical Report Risø-r-1500(EN); Riso National Laboratory: Roskilde, Denmark, 2005.

48. Theodorsen, T. General Theory of Aerodynamic Instability and the Mechanism of Flutter; Report 496; National Advisory Committee for Aeronautics: Langley Field, VA, USA, 1935.

49. Wagner, H. Über die Entstehung des dynamischen Auftriebes von Tragflügeln. ZAMM J. Appl. Math. Mech. Für Angew. Math. Und Mech. 1925, 5, 17-35. [CrossRef]

50. Manwell, J.F.; McGowan, J.G.; Rogers, A.L. Wind Energy Explained: Theory, Design and Application; Wiley: West Sussex, UK, 2002.

51. Burton, T.; Jenkins, N.; Sharpe, D.; Bossanyi, E. Wind Energy Handbook, 2nd ed.; Wiley: West Sussex, UK, 2011.

52. Hansen, M.O.L. Aerodynamics of Wind Turbines; Routledge: New York, NY, USA, 2015.

53. Peters, D.A.; Boyd, D.D.; He, C.J. Finite-State Induced-Flow Model for Rotors in Hover and Forward Flight. J. Am. Helicopter Soc. 1989, 34, 5-17. [CrossRef]

54. Yu, W.; Simao Ferreira, C.; van Kuik, G.A.M.; Baldacchino, D. Verifying the Blade Element Momentum Method in unsteady, radially varied, axisymmetric loading using a vortex ring model. Wind Energy 2017, 20, 269-288. [CrossRef]

55. Yu, W.; Simao Ferreira, C.; Van Kuik, G.A.M. The dynamic wake of an actuator disc undergoing transient load: A numerical and experimental study. Renew. Energy 2019, 132, 1402-1414. [CrossRef]

56. Leishman, J.G. Challenges in modelling the unsteady aerodynamics of wind turbines. Wind Energy 2002, 5, 85-132. [CrossRef]

57. Branlard, E. Wind Turbine Aerodynamics and Vorticity-Based Methods, Fundamentals and Recent Applications; Research Topics in Wind Energy; Springer International Publishing: Berlin/Heidelberg, Germany, 2017; Volume 7.

58. Sorensen, J.N.; Shen, W.Z. Numerical modeling of wind turbine wakes. J. Fluids Eng. 2002, 124, $393-399$. [CrossRef] 
59. Sørensen, J.N.; Mikkelsen, R.F.; Henningson, D.S.; Ivanell, S.; Sarmast, S.; Andersen, S.J. Simulation of wind turbine wakes using the actuator line technique. Philos. Trans. R. Soc. A Math. Phys. Eng. Sci. 2015, 373, 20140071. [CrossRef] [PubMed]

60. Shen, W.Z.; Zhang, J.H.; Sørensen, J.N. The actuator surface model: A new Navier-Stokes based model for rotor computations. J. Sol. Energy Eng. 2009, 131. [CrossRef]

61. Kim, T.; Oh, S.; Yee, K. Improved actuator surface method for wind turbine application. Renew. Energy 2015, 76, 16-26. [CrossRef]

62. O’Brien, J.M.; Young, T.M.; O'Mahoney, D.C.; Griffin, P.C. Horizontal axis wind turbine research: A review of commercial CFD, FE codes and experimental practices. Prog. Aerosp. Sci. 2017, 92, 1-24. [CrossRef]

63. Bisoi, S.; Haldar, S. Dynamic analysis of offshore wind turbine in clay considering soil-monopile-tower interaction. Soil Dyn. Earthq. Eng. 2014, 63, 19-35. [CrossRef]

64. Ziegler, L.; Voormeeren, S.; Schafhirt, S.; Muskulus, M. Design clustering of offshore wind turbines using probabilistic fatigue load estimation. Renew. Energy 2016, 91, 425-433. [CrossRef]

65. Kühn, M.J. Dynamics and Design Optimisation of Offshore Wind Energy Conversion Systems. Ph.D. Thesis, Delft University Wind Energy Research Institute, Delft, The Netherlands, 2001.

66. Garrad, A.D. Forces and dynamics of horizontal axis wind turbines. In Wind Energy Conversion Systems; Freris, L., Ed.; Prentice Hall: Englewood Cliffs, NJ, USA, 1990; Chapter 5, pp. 119-144.

67. Valamanesh, V.; Myers, A.T. Aerodynamic damping and seismic response of horizontal axis wind turbine towers. J. Struct. Eng. 2014, 140. [CrossRef]

68. Cerda Salzmann, D.; Van der Tempel, J. Aerodynamic Damping in the Design of Support Structures for Offshore Wind Turbines. In Proceedings of the Copenhagen Offshore Conference, Copenhagen, Denmark, 26-28 October 2005.

69. Liu, X.; Lu, C.; Li, G.; Godbole, A.; Chen, Y. Effects of aerodynamic damping on the tower load of offshore horizontal axis wind turbines. Appl. Energy 2017, 204, 1101-1114. [CrossRef]

70. Bossanyi, E.A. Wind turbine control for load reduction. Wind Energy 2003, 229-244. [CrossRef]

71. Bossanyi, E.A. Individual blade pitch control for load reduction. Wind Energy Int. J. Prog. Appl. Wind Power Convers. Technol. 2003, 6, 119-128. [CrossRef]

72. Bossanyi, E.A. Further load reductions with individual pitch control. Wind Energy Int. J. Prog. Appl. Wind Power Convers. Technol. 2005, 8, 481-485. [CrossRef]

73. Selvam, K.; Kanev, S.; van Wingerden, J.W.; van Engelen, T.; Verhaegen, M. Feedback-feedforward individual pitch control for wind turbine load reduction. Int. J. Robust Nonlinear Control. IFAC-Affil. J. 2009, 19, 72-91. [CrossRef]

74. Fischer, T.; Rainey, P.; Bossanyi, E.; Kühn, M. Study on control concepts suitable for mitigation of loads from misalgined wind and waves on offshore wind turbines supported on monopiles. Wind Eng. 2011, 5, 561-574. [CrossRef]

75. Zhang, Z.; Nielsen, S.R.K.; Blaabjerg, F.; Zhou, D. Dynamics and control of lateral tower vibrations in offshore wind turbines by means of active generator torque. Energies 2014, 7, 7746-7772. [CrossRef]

76. Stokes, G.G. On the theory of oscillatory waves. Trans. Camb. Philos. Soc. 1847, 8, 441-473.

77. Dean, R.G. Stream function representation of nonlinear ocean waves. J. Geophys. Res. 1965, 70, 4561-4572. [CrossRef]

78. Holthuijsen, L.H. Waves in Oceanic and Coastal Waters; Cambridge University Press: Cambridge, UK, 2007.

79. Henderson, A.R.; Zaaijer, M.B. Hydrodynamic loading on offshore wind turbine support structures. Eng. Integr. 2014, 25, 24-31.

80. Agarwal, P.; Manuel, L. Incorporating irregular nonlinear waves in coupled simulation and reliability studies of offshore wind turbines. Appl. Ocean Res. 2011, 33, 215-227. [CrossRef]

81. Sharma, J.N.; Dean, R.G. Second-order directional seas and associated wave forces. Soc. Pet. Eng. J. 1981, 21, 129-140. [CrossRef]

82. Marino, E.; Lugni, C.; Borri, C. A novel numerical strategy for the simulation of irregular nonlinear waves and their effects on the dynamic response of offshore wind turbines. Comput. Methods Appl. Mech. Eng. 2013, 255, 275-288. [CrossRef]

83. Morison, J.R.; O'Brien, M.P.; Johnson, J.W.; Schaaf, S.A. The force exerted by surface waves on piles. J. Pet. Technol. 1950, 189, 149-154. [CrossRef]

84. Sarpkaya, T. Wave Forces on Offshore Structures; Cambridge University Press: Cambridge, UK, 2014. 
85. MacCamy, R.C.; Fuchs, R.A. Wave Forces on Piles: A Diffraction Theory; Technical Report; Corps of Engineers: Washington, DC, USA, 1954.

86. Sumer, B.M.; Fredsøe, J. Hydrodynamics Around Cylindrical Structures; Advanced Series on Ocean Engineering; World Scientific: Singapore, 2006.

87. Liu, H.; Zhang, L.; Chen, H.; Zhang, W.; Liu, M. Wave diffraction by vertical cylinder with multiple concentric perforated walls. Ocean Eng. 2018, 166, 242-252. [CrossRef]

88. Vugts, J.H. Handbook of Bottom Founded Offshore Structures. Part 1. General Features of Offshore Structures and Theoretical Background; Eburon: Delft, The Netherlands, 2013.

89. Bachynski, E.E.; Thys, M.; Delhaye, V. Dynamic response of a monopile wind turbine in waves: Experimental uncertainty analysis for validation of numerical tools. Appl. Ocean Res. 2019, 89, 96-114. [CrossRef]

90. Barltrop, N.D.P.; Adams, A.J. Dynamics of Fixed Marine Structures, 3rd ed.; Butterworth-Heinemann: Oxford, UK, 1991.

91. Birkinshaw, M.; Easson, W.J.; Greated, C.A.; Webb, R.M. Breaking wave design: A case history. Proc. ICE 1988, 85, 415-433. [CrossRef]

92. Jacobsen, N.G.; Fuhrman, D.R.; Fredsøe, J. A wave generation toolbox for the open-source CFD library: OpenFoam $(\mathrm{B}$. Int. J. Numer. Methods Fluids 2012, 70, 1073-1088. [CrossRef]

93. Alagan Chella, M.; Bihs, H.; Myrhaug, D.; Muskulus, M. Breaking characteristics and geometric properties of spilling breakers over slopes. Coast. Eng. 2015, 95, 4-19. [CrossRef]

94. Marino, E.; Borri, C.; Lugni, C. Influence of wind-waves energy transfer on the impulsive hydrodynamic loads acting on offshore wind turbines. J. Wind Eng. Ind. Aerodyn. 2011, 99, 767-775. [CrossRef]

95. Mo, W.; Jensen, A.; Liu, P.L.F. Plunging solitary wave and its interaction with a slender cylinder on a sloping beach. Ocean Eng. 2013, 74, 48-60. [CrossRef]

96. Xiao, H.; Huang, W. Three-dimensional numerical modeling of solitary wave breaking and force on a cylinder pile in a coastal surf zone. J. Eng. Mech. 2014, 141, A4014001. [CrossRef]

97. Alagan Chella, M.; Bihs, H.; Myrhaug, D.; Muskulus, M. Breaking solitary waves and breaking wave forces on a vertically mounted slender cylinder over an impermeable sloping seabed. J. Ocean Eng. Mar. Energy 2017, 3, 1-19. [CrossRef]

98. Marino, E.; Borri, C.; Peil, U. A fully nonlinear wave model to account for breaking wave impact loads on offshore wind turbines. J. Wind Eng. Ind. Aerodyn. 2011, 99, 483-490. [CrossRef]

99. Chan, E.S.; Cheong, H.F.; Tan, B.C. Laboratory study of plunging wave impacts on vertical cylinders. Coast. Eng. 1995, 25, 87-107. [CrossRef]

100. Bredmose, H.; Slabiak, P.; Sahlberg-Nielsen, L.; Schlütter, F. Dynamic excitation of monopiles by steep and breaking waves: Experimental and numerical study. In Proceedings of the ASME 2013 32nd International Conference on Ocean, Offshore and Arctic Engineering, Citeseer, Nantes, France, 9-14 June 2013.

101. Sodhi, D.S. An ice-structure interaction model. In Studies in Applied Mechanics; Elsevier: Amsterdam, The Netherlands, 1995; Volume 42, pp. 57-75.

102. Määttänen, M. Numerical model for ice-induced vibration load lock-in and synchronization. In Proceedings of the 14th International Symposium on Ice, Potsdam, NY, USA, 27-31 July 1998; pp. 923-930.

103. Kärnä, T.; Kamesaki, K.; Tsukuda, H. A numerical model for dynamic ice-structure interaction. Comput. Struct. 1999, 72, 645-658. [CrossRef]

104. Hendrikse, H.; Metrikine, A.V. Interpretation and prediction of ice induced vibrations based on contact area variation. Int. J. Solids Struct. 2015, 75, 336-348. [CrossRef]

105. Hendrikse, H.; Ziemer, G.; Owen, C.C. Experimental validation of a model for prediction of dynamic ice-structure interaction. Cold Reg. Sci. Technol. 2018, 151, 345-358. [CrossRef]

106. Willems, T.; Hendrikse, H. Coupled Simulation of Ice-Structure Interaction of Offshore Wind Turbines in BHawC Using VANILLA. In Proceedings of the 25th International Conference on Port and Ocean engineering under Arctic Conditions, Delft, The Netherlands, 9-13 June 2019.

107. Seidel, M.; Hendrikse, H. Analytical assessment of sea ice-induced frequency lock-in for offshore wind turbine monopiles. Mar. Struct. 2018, 60, 87-100. [CrossRef]

108. Reese, L.C.; Van Impe, W.F. Single Piles and Pile Groups under Lateral Loading, 2nd ed.; CRC Press: Boka Raton, FL, USA, 2011.

109. Matlock, H. Correlations for design of laterally loaded piles in soft clay. Offshore Technol. Civ. Eng. Hall Fame Pap. Early Years 1970, 77-94. 
110. Cox, W.R.; Reese, L.C.; Grubbs, B.R. Field Testing of laterally loaded piles in sand. In Proceedings of the Sixth Annual Offshore Technology Conference, Dallas, TX, USA, 6-9 May 1974; pp. 459-472.

111. Reese, L.C.; Cox, W.R.; Koop, F.D. Analysis of laterally loaded piles in sand. In Proceedings of the Sixth Annual Offshore Technology Conference, Dallas, TX, USA, 6-9 May 1974; pp. 473-484.

112. Leth, C.T.; Sørensen, S.P.H.; Klinkvort, R.T.; Augustesen, A.H.; Ibsen, L.B.; Hededal, O. A snapshot of present research at AAU and DTU on large-diameter piles in coarse-grained materials. In The Nordic Geotechnical Meeting; Dansk Geoteknisk Forening: Kongens Lyngby, Denmark, 2012; pp. 491-498.

113. Shadlou, M.; Bhattacharya, S. Dynamic stiffness of monopiles supporting offshore wind turbine generators. Soil Dyn. Earthq. Eng. 2016, 88, 15-32. [CrossRef]

114. Sørensen, S.P.H.; Ibsen, L.B.; Augustesen, A.H. Effects of diameter on initial stiffness of p-y curves for large-diameter piles in sand. In Numerical Methods in Geotechnical Engineering; CRC Press: Boka Raton, FL, USA, 2010; pp. 923-928.

115. Kallehave, D.; Thilsted, C.L.; Liingaard, M. Modification of the API py formulation of initial stiffness of sand. In Proceedings of the Offshore Site Investigation and Geotechnics: Integrated Technologies-Present and Future, London, UK, 12-14 September 2012; Society of Underwater Technology: London, UK, 2012.

116. Houlsby, G.T.; Abadie, C.N.; Beuckelaers, W.J.A.P.; Byrne, B.W. A model for nonlinear hysteretic and ratcheting behaviour. Int. J. Solids Struct. 2017, 120, 67-80. [CrossRef]

117. Liu, H.Y.; Abell, J.A.; Diambra, A.; Pisanò, F. Modelling the cyclic ratcheting of sands through memory-enhanced bounding surface plasticity. Géotechnique 2019, 69, 783-800. [CrossRef]

118. Schafhirt, S.; Page, A.M.; Eiksund, G.R.; Muskulus, M. Influence of soil parameters on the fatigue lifetime of offshore wind turbines with monopile support structure. Energy Procedia 2016, 94, 347-356. [CrossRef]

119. Achmus, M.; Kuo, Y.S.; Abdel-Rahman, K. Behavior of monopile foundations under cyclic lateral load. Comput. Geotech. 2009, 36, 725-735. [CrossRef]

120. Damgaard, M.; Bayat, M.; Andersen, L.V.; Ibsen, L.B. Assessment of the dynamic behaviour of saturated soil subjected to cyclic loading from offshore monopile wind turbine foundations. Comput. Geotech. 2014, 61, 116-126. [CrossRef]

121. Jardine, R.J.; Puech, A.; Andersen, K.H. Cyclic loading of offshore piles: Potential effects and practical design. In Proceedings of the 7th International Conference on Offshore Site Investigations and Geotechnics: Integrated Geotechnologies-Present and Future, London, UK, 12-14 September 2012.

122. Pisanò, F.; Gavin, K. General Report for TC209: Offshore Geotechnics. In Proceedings of the 19th International Conference on Soil Mechanics and Geotechnical Engineering, Seoul, Korea, 17-22 September 2017.

123. Dutta, S.C.; Roy, R. A critical review on idealization and modeling for interaction among soil-foundationstructure system. Comput. Struct. 2002, 80, 1579-1594. [CrossRef]

124. Zaaijer, M.B. Foundation modelling to assess dynamic behaviour of offshore w ind turbines. Appl. Ocean Res. 2006, 28, 45-57. [CrossRef]

125. Bhattacharya, S.; Adhikari, S. Experimental validation of soil-structure interaction of offshore wind turbines. Soil Dyn. Earthq. Eng. 2011, 31, 805-816. [CrossRef]

126. Andersen, L.V.; Vahdatirad, M.J.; Sichani, M.T.; Sørensen, J.D. Natural frequencies of wind turbines on monopile foundations in clayey soils-A probabilistic approach. Comput. Geotech. 2012, 43, 1-11. [CrossRef]

127. Damgaard, M.; Zania, V.; Andersen, L.V.; Ibsen, L.B. Effects of soil-structure interaction on real time dynamic response of offshore wind turbines on monopiles. Eng. Struct. 2014, 75, 388-401. [CrossRef]

128. Häfele, J.; Hübler, C.; Gebhardt, C.G.; Rolfes, R. An improved two-step soil-structure interaction modeling method for dynamical analyses of offshore wind turbines. Appl. Ocean Res. 2016, 55, 141-150. [CrossRef]

129. Varun.; Assimaki, D.; Gazetas, G. A simplified model for lateral response of large diameter caisson foundations —Linear elastic formulation. Soil Dyn. Earthq. Eng. 2009, 29, 268-291. [CrossRef]

130. Versteijlen, W.G.; Metrikine, A.V.; van Dalen, K.N. A method for identification of an effective Winkler foundation for large-diameter offshore wind turbine support structures based on in-situ measured small-strain soil response and 3D modelling. Eng. Struct. 2016, 124, 221-236. [CrossRef]

131. Corciulo, S.; Zanoli, O.; Pisanò, F. Transient response of offshore wind turbines on monopiles in sand: role of cyclic hydro-mechanical soil behaviour. Comput. Geotech. 2017, 83, 221-238. [CrossRef]

132. Corciulo, S.; Zanoli, O.; Pisanò, F. Supporting the Engineering Analysis of Offshore Wind Turbines Through Advanced Soil-Structure 3D Modelling. In Proceedings of the ASME 2017 36th International Conference on Ocean, Offshore and Arctic Engineering, Trondheim, Norway, 25-30 June 2017. 
133. Andersen, L. Assessment of lumped-parameter models for rigid footings. Comput. Struct. 2010, 88, $1333-1347$. [CrossRef]

134. Damgaard, M.; Ibsen, L.B.; Andersen, L.V.; Andersen, J.K.F. Cross-wind modal properties of offshore wind turbines identified by full scale testing. J. Wind Eng. Ind. Aerodyn. 2013, 116, 94-108. [CrossRef]

135. Carswell, W.; Johansson, J.; Løvholt, F.; Arwade, S.; Madshus, C.; DeGroot, D.J.; Myers, A.T. Foundation damping and the dynamics of offshore wind turbine monopiles. Renew. Energy 2015, 80, 724-736. [CrossRef]

136. Achmus, M.; Akdag, C.T.; Thieken, K. Load-bearing behavior of suction bucket foundations in sand. Appl. Ocean Res. 2013, 43, 157-165. [CrossRef]

137. Zhang, J.H.; Chen, Z.Y.; Li, F. Three dimensional limit analysis of suction bucket foundations. Ocean Eng. 2010, 37, 790-799. [CrossRef]

138. Zhang, P.; Xiong, K.; Ding, H.; Le, C. Anti-liquefaction characteristics of composite bucket foundations for offshore wind turbines. J. Renew. Sustain. Energy 2014, 6, 053102. [CrossRef]

139. van Wijngaarden, M.; Meijers, P.; Raaijmakers, T.; de Jager, R.; Gavin, K. Gravity based foundations for offshore wind turbines: Cyclic loading and liquefaction. In Proceedings of the International Conference on Offshore Mechanics and Arctic Engineering, American Society of Mechanical Engineers, Madrid, Spain, 17-22 June 2018.

140. Buhl, M.L.; Wright, A.D.; Pierce, K.G. Wind turbine design codes: A comparison of the structural response. In Proceedings of the American Society of Mechanical Engineers (ASME) Wind Energy Symposium, Reno, NV, USA, 10-13 January 2000.

141. Passon, P.; Kühn, M.; Butterfield, S.; Jonkman, J.; Camp, T.; Larsen, T.J. OC3 - benchmark exercise of aero-elastic offshore wind turbine codes. J. Phys. Conf. Ser. 2007, 75, 012071. [CrossRef]

142. Vorpahl, F.R.; Van Wingerde, A.; Blunk, M.; Busmann, H.G.; Kleinhansl, S.; Bolton, M.; Bolon, M.; Böker, C.; Kaufer, D.; Azcona, J.; et al. Validation of a Finite Element Based Simulation Approach For OffshoreWind Turbines Within IEA Wind Annex XXIII - Simulation Challenges And Results For a 5-MW Turbine On a Tripod Substructure. In Proceedings of the The Nineteenth International Offshore and Polar Engineering Conference, Osaka, Japan, 21-26 June 2009.

143. Jonkman, J.; Musial, W. Offshore Code Comparison Collaboration (OC3) for IEA Task 23 Offshore Wind Technology and Deployment; Technical Report; National Renewable Energy Laboratory: Golden, CO, USA, 2010.

144. Popko, W.; Vorpahl, F.; Zuga, A.; Kohlmeier, M.; Jonkman, J.; Robertson, A.; Larsen, T.J.; Yde, A.; Sætertrø, K.; Okstad, K.M.; et al. Offshore Code Comparison Collaboration Continuation (OC4), Phase 1 - Results of Coupled Simulations of an Offshore Wind Turbine With Jacket Support Structure. In Proceedings of the Twenty-Second International Offshore and Polar Engineering Conference, Rhodes, Greece, 17-22 June 2012; International Society of Offshore and Polar Engineers: Mountain View, CA, USA, 2012.

145. Vorpahl, F.; Strobel, M.; Jonkman, J.M.; Larsen, T.J.; Passon, P.; Nichols, J. Verification of aero-elastic offshore wind turbine design codes under IEA Wind Task XXIII. Wind Energy 2014, 17, 519-547. [CrossRef]

146. Robertson, A.N.; Wendt, F.F.; Jonkman, J.M.; Popko, W.; Vorpahl, F.; Stansberg, C.T.; Bachynski, E.E.; Bayati, I.; Beyer, F.; de Vaal, J.B.; et al. OC5 Project Phase I: Validation of Hydrodynamic Loading on a Fixed Cylinder; Technical Report NREL/CP-5000-63567; National Renewable Energy Laboratory: Golden, CO, USA, 2015.

147. Robertson, A.N.; Wendt, F.; Jonkman, J.M.; Popko, W.; Borg, M.; Bredmose, H.; Schlutter, F.; Qvist, J.; Bergua, R.; Harries, R.; et al. OC5 Project Phase Ib: Validation of hydrodynamic loading on a fixed, flexible cylinder for offshore wind applications. Energy Procedia 2016, 94, 82-101. [CrossRef]

148. Hansen, M.H.; Thomsen, K.; Fuglsang, P.; Knudsen, T. Two methods for estimating aeroelastic damping of operational wind turbine modes from experiments. Wind Energy 2006, 9, 179-191. [CrossRef]

149. Versteijlen, W.G.; Metrikine, A.V.; Hoving, J.S.; Smid, E.; de Vries, W.E. Estimation of the vibration decrement of an offshore wind turbine support structure caused by its interaction with soil. In Proceedings of the EWEA Offshore 2011 Conference, Amsterdam, The Netherlands, 29 November-1 December 2011.

150. Osgood, R.; Bir, G.; Mutha, H.; Peeters, B.; Luczak, M.; Sablon, G. Full-scale modal wind turbine tests: Comparing shaker excitation with wind excitation. In Structural Dynamics and Renewable Energy; Springer: Berlin/Heidelberg, Germany, 2011; Volume 1, pp. 113-124.

151. Damgaard, M.; Andersen, J.K.F.; Ibsen, L.B.; Andersen, L.V. Natural frequency and damping estimation of an offshore wind turbine structure. In Proceedings of the Twenty-second International Offshore and Polar Engineering Conference, Rhodes, Greece, 17-22 June 2012; International Society of Offshore and Polar Engineers: Mountain View, CA, USA, 2012. 
152. Shirzadeh, R.; Devriendt, C.; Bidakhvidi, M.A.; Guillaume, P. Experimental and computational damping estimation of an offshore wind turbine on a monopile foundation. J. Wind Eng. Ind. Aerodyn. 2013, 120, 96-106. [CrossRef]

153. Devriendt, C.; Jordaens, P.; de Sitter, G.; Guillaume, P. Damping estimation of an offshore wind turbine on a monopile foundation. IET Renew. Power Gener. 2013, 7, 401-412. [CrossRef]

154. Devriendt, C.; Weijtjens, W.; El-Kafafy, M.; De Sitter, G. Monitoring resonant frequencies and damping values of an offshore wind turbine in parked conditions. IET Renew. Power Gener. 2014, 8, 433-441. [CrossRef]

155. Shirzadeh, R.; Weijtjens, W.; Guillaume, P.; Devriendt, C. The dynamics of an offshore wind turbine in parked conditions: A comparison between simulations and measurements. Wind Energy 2015, 18, 1685-1702. [CrossRef]

156. Versteijlen, W.G.; Renting, F.W.; van der Valk, P.L.C.; Bongers, J.; van Dalen, K.N.; Metrikine, A.V. Effective soil-stiffness validation: Shaker excitation of an in-situ monopile foundation. Soil Dyn. Earthq. Eng. 2017, 102, 241-262. [CrossRef]

157. Page, A.M.; Næss, V.; De Vaal, J.B.; Eiksund, G.R.; Nygaard, T.A. Impact of foundation modelling in offshore wind turbines: Comparison between simulations and field data. Mar. Struct. 2019, 64, 379-400. [CrossRef]

158. Rudolph, D.; Raaijmakers, T.; Stam, C.J. Time-dependent scour development under combined current and wave conditions-hindcast of field measurements. In Proceedings of the Fourth International Conference on Scour and Erosion ICSE, Tokyo, Japan, 5-7 November 2008; Volume 4, pp. 340-347.

159. Raaijmakers, T.; Rudolph, D. Time-dependent scour development under combined current and waves conditions-laboratory experiments with online monitoring technique. In Proceedings of the Fourth International Conference on Scour and Erosion ICSE, Tokyo, Japan, 5-7 November 2008; Volume 4, pp. 152-161.

160. Meirovitch, L. Computational Methods in Structural Dynamics; Sijthoff \& Noordhoff: Alphen aan den Rijn, The Netherlands, 1980.

161. Voormeeren, S.N.; van der Valk, P.L.C.; Noriter, B.P.; Molenaar, D.; Rixen, D.J. Accurate and efficient modeling of complex offshore wind turbine support structures using augmented superelements. Wind Energy 2014, 7, 1035-1054. [CrossRef]

162. Passon, P.; Branner, K. Condensation of long-term wave climates for the fatigue design of hydrodynamically sensitive offshore wind turbine support structures. Ships Offshore Struct. 2016, 11, 142-166. [CrossRef]

163. Halfpenny, A. Dynamic Analysis of both on and Offshore Wind Turbines in the Frequency Domain. Ph.D. Thesis, University of London, London, UK, 1998.

164. Van der Tempel, J. Design of Support Structures for Offshore Wind Turbines. Ph.D. Thesis, Delft University Wind Energy Research Institute, Delft, The Netherlands, 2006.

165. de Klerk, D.; Rixen, D.J.; Voormeeren, S.N. General framework for dynamic substructuring: History, review and classification of techniques. AIAA J. 2008, 46, 1169-1181. [CrossRef]

166. Van der Valk, P.L.C.; Voormeeren, S.N. An overview of modeling approaches for complex offshore wind turbine support structures. In Proceedings of the ISMA2012-USD2012, Leuven, Belgium, 17-19 September 2012; pp. 17-19.

167. Rixen, D.J.; van der Valk, P.L.C. An impulse based substructuring approach for impact analysis and load case simulations. J. Sound Vib. 2013, 26, 7174-7190. [CrossRef]

168. Seidel, M. Wave induced fatigue loads. Stahlbau 2014, 83, 535-541. [CrossRef]

169. Passon, P. Damage equivalent wind-wave correlations on basis of damage contour lines for the fatigue design of offshore wind turbines. Renew. Energy 2015, 81, 723-736. [CrossRef]

170. Stieng, L.E.; Muskulus, M. Reducing the number of load cases for fatigue damage assessment of offshore wind turbine support structures using a simple severity-based sampling method. Wind Energy Sci. 2018, 3, 805-818. [CrossRef]

171. Zwick, D.; Muskulus, M. The simulation error caused by input loading variability in offshore wind turbine structural analysis. Wind Energy 2015, 18, 1421-1432. [CrossRef]

172. Müller, K.; Cheng, P.W. Validation of uncertainty in IEC damage calculations based on measurements from alpha ventus. Energy Procedia 2016, 94, e145. [CrossRef]

173. Hübler, C.; Gebhardt, C.G.; Rolfes, R. Methodologies for fatigue assessment of offshore wind turbines considering scattering environmental conditions and the uncertainty due to finite sampling. Wind Energy 2018, 21, 1092-1105. [CrossRef]

174. Hübler, C.; Weijtjens, W.; Gebhardt, C.G.; Rolfes, R.; Devriendt, C. Validation of Improved Sampling Concepts for Offshore Wind Turbine Fatigue Design. Energies 2019, 12, 603. [CrossRef] 
175. Borgman, L.E. Random hydrodynamic forces on objects. Ann. Math. Stat. 1967, 38, 37-51. [CrossRef]

176. Borgman, L.E. Spectral analysis of ocean wave forces on piling. J. Waterw. Harb. Div. Proc. ASCE 1967, 2, $129-156$.

177. Naess, A.; Yim, S.C.S. Stochastic response of offshore structures excited by drag forces. J. Eng. Mech. 1996, 122, 442-448. [CrossRef]

178. Kareem, A. Nonlinear wind velocity term and response of compliant offshore structures. J. Eng. Mech. 1984, 110, 1573-1578. [CrossRef]

179. Kareem, A.; Shao, J.; Tognarelli. Surge response statistics of tension leg platforms under wind and wave loads: A statistical quadratization approach. Probabilistic Eng. Mech. 1995, 10, 225-240. [CrossRef]

180. Kareem, A.; Tognarelli, M.A.; Gurley, K.R. Modeling and analysis of quadratic term in the wind effects on structures. J. Wind Eng. Ind. Aerodyn. 1998, 74-76, 1101-1110. [CrossRef]

181. Carassale, L.; Kareem, A. Modeling nonlinear systems by Volterra series. J. Eng. Mech. 2010, 136, 801-818. [CrossRef]

(C) 2020 by the authors. Licensee MDPI, Basel, Switzerland. This article is an open access article distributed under the terms and conditions of the Creative Commons Attribution (CC BY) license (http:// creativecommons.org/licenses/by/4.0/). 